BULLETIN Bulletin hispanique

HISPANIQUE Université Michel de Montaigne Bordeaux

$111-2 \mid 2009$

Varia

\title{
"El ondear del aire": Juan Ramón Jiménez y la poesía española de posguerra (1939-1960)
}

Notas de aproximación

Juan José Lanz

\section{OpenEdition}

\section{Journals}

Edición electrónica

URL: http://journals.openedition.org/bulletinhispanique/1017

DOI: 10.4000/bulletinhispanique.1017

ISSN: $1775-3821$

Editor

Presses universitaires de Bordeaux

\section{Edición impresa}

Fecha de publicación: 1 diciembre 2009

Paginación: 473-518

ISBN: 978-2-86781-617-8

ISSN: 0007-4640

Referencia electrónica

Juan José Lanz, «"El ondear del aire": Juan Ramón Jiménez y la poesía española de posguerra (1939-1960) », Bulletin hispanique [En línea], 111-2 | 2009, Publicado el 01 diciembre 2012, consultado el 19 abril 2019. URL : http://journals.openedition.org/bulletinhispanique/1017 ; DOI : 10.4000/ bulletinhispanique.1017 


\title{
"El ondear del aire": Juan Ramón Jiménez y la poesía española de posguerra (1939-1960). Notas de aproximación
}

\author{
JUAN José LANZ \\ $U P V / E H U$ - Espagne
}

Cet article est consacré à la présence centrale de Juan Ramón Jiménez et de son ouvre dans la poésie espagnole d'après-guerre (1939-1960). Cette présence est attestée non seulement par les relations épistolaires qu'il entretient avec de nombreux écrivains mais aussi par la publication constante de ses poèmes dans les revues de la péninsule et par les échos textuels qu'en laissent percevoir les auvres de divers poètes. Ainsi, les poètes espagnols d'après-guerre entretiennent-ils un dialogue fécond avec la poésie de celui qu'ils prennent pour l'un de leurs principaux maîtres.

En este articulo se repasa la presencia fundamental que tiene Juan Ramón Jiménez y su obra en la poesía española de posguerra (1939-1960). Esa presencia se testimonia no sólo a través de la relación epistolar que mantiene con diversos autores, sino también a través de la constante publicación de poemas en revistas peninsulares y sobre todo a través de los ecos textuales que diferentes poetas muestran en sus obras. De este modo, los poetas españoles de posguerra establecen un diálogo muy productivo con la poesía del que consideran como uno de sus principales maestros.

In this article, we will see how fundamental the presence of Juan Ramon Jimenez and his work was -in the Spanish poetry of the post-war period (1939-1960). That presence is attested not only by the epistolary relations he kept up with many writers, but also by his constant publication of poems in peninsular magazines as well as the textual echoes that different poets bring in their works. Thus, the Spanish poets of the post-war era established a very productive dialog with the poetry of the man they took for one of their greatest masters.

$B H i$, Tome $111, \mathrm{n}^{\circ} 2$ - décembre 2009 - p. 473 à 518. 
Mots-clés : Juan Ramón Jiménez - Poésie espagnole d'après-guerre (1939-1960) - Intertextualité.

«T UAN Ramón pertenece al grupo de excepcionales creadores de amplia órbita. Si hay un nombre que represente poéticamente el siglo XX español, ése es el suyo. [...] sólo él ha cambiado fundamentalmente la estructura de nuestra lírica contemporánea» ${ }^{1}$. Así escribía, en el número homenaje que la revista Ínsula dedicaba al poeta moguereño con motivo de la concesión del Premio Nobel de Literatura en 1956, José Hierro, uno de los poetas más destacados de la posguerra, que había defendido el magisterio de Juan Ramón para su poesía. Hoy sabemos ${ }^{2}$ que, cuando el comité de los Premios Nobel comenzó a recabar información en 1952 sobre algún candidato español, el nombre de Juan Ramón Jiménez no fue avalado por ningún intelectual español de relieve, y contó como valedor con el apoyo del catedrático de poesía de Oxford C. M. Bowra, que lo consideraba como «el más grande poeta vivo». Pero también es verdad que, al menos desde $1948^{3}$, un grupo de poetas venía promoviendo la candidatura del andaluz al preciado galardón, aunque, como lamentaba el anónimo editor de Espadaña, «apenas si ha encontrado eco en Espańa la idea de solicitar el Premio Nobel de Literatura para Juan Ramón Jiménez» ${ }^{4}$.

Tal como escribía Rafael Alberti, evocando el influjo juanramoniano en los años veinte, «jamás poeta español iba a ser más querido y escuchado por una rutilante generación de poetas». Luis Cernuda, por el contrario, que recuerda cómo, «entre 1917 y 1930, ejerce este poeta una verdadera dictadura en el reducido ambiente literario español», iba a apuntar a la altura

1. José Hierro, "Juan Ramón, comparado", Ínsula, n 128-129, julio-agosto de 1957, pág. 11. José Hierro reproduciría estas palabras en «Poesía sinfónica, poesía de cámara», Peña Labra, vol. XX, 1976, pág. 22.

2. Vid. Lola Galán, «Juan Ramón, Nobel a pesar de España», El País, 18-XI-2007.

3. Ramón de Garciasol, «El Premio Nobel para Juan Ramón Jiménez. Carta abierta a Ricardo Gullón», Ínsula, n² 27, marzo de 1948, pág. 7. Juan Ramón le agradecerá el artículo en una carta fechada en Río Piedras el 24 de diciembre de 1952 (Cartas literarias, Barcelona, Bruguera, 1977, pág. 209). El artículo de Garciasol venía a responder al artículo de Ricardo Gullón, "Juan Ramón y la poesía», que reivindicaba la poesía del moguereńo, en Ínsula, $\mathrm{n}^{\circ} 23$, noviembre de 1947 , pág. 3. Sobre el asunto se insistiría en una nota en la sección «La Flecha en el Tiempo», «El Premio Nobel y Juan Ramón Jiménez», Ínsula, n ${ }^{\circ} 48$, diciembre de 1949, pág. 8. Seguramente haciéndose eco del trabajo de Ricardo Gullón publicado en aquel número: «Un canto para la poesía», Insula, $\mathrm{n}^{\circ}$ 48, diciembre de 1949, pág. 3. Véase también Ricardo Molina, "Juan Ramón Jiménez», Cántico, n 8 , primera época, diciembre de 1948-enero de 1949, pág. 12.

4. «El Premio Nobel» en Espadaña, n 33, 1948, pág. 705 de la ed. facsímil. 
de 1957, evocando aquel influjo: «el ambiente y la sociedad española han cambiado, y Jiménez parece sobrevivirse a sí mismo y a su época. La opinión ya no le es favorable» ${ }^{5}$. Ésa es justamente la opinión que recogería dos años más tarde José María Castellet en el prólogo programático de Veinte años de poesía española (1939-1959), para no incluir en la selección antológica ningún poema del moguereño, «a causa de la pérdida de vigencia histórica de la escasa obra que publicó en los últimos veinte años» ${ }^{6}$. El propio Cernuda ya había apuntado en 1941, en un artículo publicado en El Hijo Pródigo, «el juicio de la generación actual, menos favorable para la obra de Juan Ramón Jiménez» ${ }^{7}$. ¿Qué había sucedido en la valoración del poeta de Moguer en ese arco temporal de cuarenta ańos que se inicia con la publicación del Diario de un poeta reciencasado y concluye con su muerte? ¿Cuál era la verdadera presencia de la poesía de Juan Ramón en los poetas más jóvenes que habían comenzado a escribir tras la guerra civil? ¿Cuál es la relación que establecen las nuevas promociones bajo la España de la dictadura con el poeta exiliado? Porque, pese a opiniones contrarias como la de Cernuda o Castellet, no cabe duda de que buena parte de la mejor poesía de la posguerra española se escribe sobre el papel pautado que traza el poeta moguereño, y muy atenta a los designios que marcan su evolución poética en el exilio.

$\mathrm{Si}$ he referido las palabras de los dos poetas del 27 es porque cualquier planteamiento sobre la presencia juanramoniana, sea secreta ${ }^{8}$ o declarada ${ }^{9}$,

5. Luis Cernuda, Obra completa, ed. Derek Harris y Luis Maristany, Madrid, Siruela, 1994, vol. II, pág. 151. En la versión publicada en México en la Cultura, nº 291, 17-X-1954, la idea se expresaba en términos aún más radicales: «Hoy quizá su poesía alcance el nivel más bajo en la opinión de los lectores, y no pocos de éstos consideren a su autor como un escritor pasado de moda».

6. José María Castellet, Veinte años de poesía española (1939-1959), Barcelona, Seix Barral, 1960, $2^{a}$ ed., pág. 21.

7. Luis Cernuda, Op. cit., vol. III, p. 174. El artículo se publicó por primera vez en el Bulletin of Spanish Studies, vol. XIX, n 76 , octubre de 1942. Fue reproducido posteriormente en la revista mexicana El Hijo Pródigo, vol. I, n 3, junio de 1943. Juan Ramón le respondería con una carta «A Luis Cernuda», publicada en el número siguiente de la revista mexicana y recogida en Cartas literarias..., págs. 54-60.

8. Vid. José Luis García Martín, «Una historia secreta: Juan Ramón Jiménez y la poesía española de posguerra», Pilar Gómez Védate, ed., Estudios sobre Juan Ramón Jiménez editados en conmemoración del primer centenario de su nacimiento, Puerto Rico, Recinto Universitario de Mayagüez, 1981, págs. 195-226.

9. Fanny Rubio, «Medio siglo de poetas al sol del maestro», El País, sección Libros, n 14, 27-XII-1981, pág. 7. Fanny Rubio, «Juan Ramón Jiménez en la poesía española de postguerra", Actas del Congreso Internacional Conmemorativo del Centenario de Juan Ramón Jiménez, celebrado en La Rábida, Huelva, Diputación Provincial de Huelva, 1983, vol. II, págs. 515-522. 
en las generaciones españolas de posguerra ha de partir del debate sobre la poesía pura que acontece en los prolegómenos de la guerra civil y que va a condicionar buena parte del desarrollo estético de la posguerra, tanto en la España interior como en la peregrina. Efectivamente, la batalla en torno a la poesía pura ${ }^{10}$, que va a acontecer a partir de 1933, en que Juan Ramón comienza a publicar su ideario estético en El Sol, y que se va a extender en los ańos siguientes, con la proclamación de una nueva estética, «impura», como reclamará Pablo Neruda desde el conocido manifiesto del primer número de Caballo verde para la poesía, en octubre de 1935, va a condicionar las primeras propuestas poéticas que aparezcan una vez concluida la guerra civil, no para plantear una nueva edición de aquel debate, inclinado el fiel de la balanza definitivamente hacia el polo de la rehumanización, sino para establecerlo en los términos del compromiso político en que habían derivado aquellas propuestas. En este sentido, el pensamiento estético juanramoniano marca la pauta de la reflexión poética de la posguerra, para plantear una relectura interesante de su obra. Su presencia es constante en los poetas y en las publicaciones de posguerra, y si algunas veces (menos de las que generalmente se piensa) se cuestionan sus planteamientos estéticos, no cabe duda de que éstos sirven de estímulo para interiorizar en un debate personal una buena parte de la reflexión poética que se establece en los años posteriores a la guerra civil. En este sentido, no cabe ver un enfrentamiento excluyente en la poesía de posguerra entre la presencia de Machado y la del poeta moguereño, ni menos aún una vinculación política en la defensa pública de la preferencia por alguno de estos poetas. Como muy bien señalará en 1943 Gerardo Diego en un artículo sobre la «Presencia de Unamuno poeta», publicado en Cisneros, si en los versos de un poeta de ese momento puede verse proyectada la sombra de Antonio Machado, junto a ella ha de verse la huella del Unamuno poeta, pero frente a esa influencia «sólo se eleva al otro lado la de Juan Ramón Jiménez, demasiado conocida para que pueda ser olvidada. Su influencia principalmente estética y técnica» ${ }^{11}$. En este sentido, Hierro se quejaba años más tarde: "No entiendo por qué razón hay que decidirse entre uno y otro» ${ }^{12}$. Y es que, como había dicho el poeta santanderino unos años antes, "Juan Ramón y Antonio Machado [...] trataban de cantar lo que el hombre es» ${ }^{13}$. Como "poesía humanísima»

10. Juan Cano Ballesta, La poesía española entre pureza y revolución (1930-1936), Madrid, Gredos, 1972, passim, pero especialmente págs. 201-227.

11. Gerardo Diego, «Presencia de Unamuno poeta», Cisneros, n 7, 1943, pág. 67.

12. José Hierro, "Un Nobel entero para nuestra poesía», La Estafeta Literaria, n 278 , 1963, pág. 4.

13. José Hierro, «Hölderlin», Guardados en la sombra. Textos de la prehistoria literaria de José 
iba a caracterizar Gerardo Diego, en un artículo publicado en 1948, la producción última del moguereño ${ }^{14}$. Si Rubén Darío cierra una época de la poesía española, Juan Ramón, su heredero, inaugura un nuevo período, determina una estructura nueva para la lírica en lengua espańola a la que no podrán (ni querrán) sustraerse los poetas más jóvenes, que muchas veces leen en su purismo, en la exigencia de «que la intención sea pura, que se distinga la poesía del verso» ${ }^{15}$, una dimensión de la lucha anti-retórica que ellos llevan a cabo en sus versos, y perfilan claramente la dimensión humana de su escritura. Y, por otro lado, si la poesía de Antonio Machado es «recuperada» en los primeros años de la posguerra en la lectura de Dionisio Ridruejo y la de Unamuno lo es de la mano de Luis Felipe Vivanco, Juan Ramón, en la dictadura recién instaurada, recibió los embates de las filas falangistas, que desde la revista $\mathrm{Haz}$ criticaban su "cómoda pureza» ${ }^{16}$, o que, como José María Alfaro en el prólogo a la edición española de La poesía de Juan Ramón Jiménez, de Carlo Bo, lo veían como «el ápice del sensibilismo intimista y expresivo", y criticaban su "torre de marfil», «el clima mallarmeano, en el que crecen sus recónditos y deslumbrantes hallazgos líricos», «modelo de egoísmo lírico», "hermético e inaprensible pontífice de la sensibilidad», que ha marcado «el adueñamiento, por un bando poético, de las expresiones juanramonianas» ${ }^{17}$. Los tres poetas marcarán buena parte del curso que desarrolle la poesía española de posguerra en los primeros años, aunque muchas veces sean otros los nombres que se escriban.

Llama la atención, frente a la imagen que había cultivado el poeta en los años anteriores a la guerra civil, la voluntad de Juan Ramón en el exilio de tener una presencia en las publicaciones poéticas, no sólo de la España peregrina, sino también de la interior. Así lo confiesa en carta a Tomás Segovia en 1953 ó 1954: «En España colaboro en una porción de revistas madrileñas y provincianas y las cartas de los jóvenes de esas revistas son realmente conmovedoras» ${ }^{18}$. Lejos ya los gestos displicentes que llevaron al poeta a retirar los textos de la antología de Gerardo Diego, en su segunda edición, a partir del enfrentamiento creciente que tuvo desde 1933 con una parte de

Hierro, ed. de Luce López-Baralt, Madrid, Cátedra, 2002, pág. 39.

14. Gerardo Diego, «Nostalgia de Juan Ramón», Alférez, n² 21, 1948. Recogido en Obras completas, ed. José Luis Bernal, Madrid, Alfaguara, 2000, t. VIII, pág. 54.

15. José Hierro, "Juan Ramón...», pág. 11.

16. Fanny Rubio, Revistas poéticas españolas, 1939-1975, Madrid, Turner, 1976, págs. 87-88. Existe reedición reciente: Alicante, Universidad de Alicante, 2003.

17. José María Alfaro, «Prólogo» a Carlo Bo, La poesía con Juan Ramón Jiménez, Madrid, Editorial Hispánica, 1943, págs. 11-14.

18. Juan Ramón Jiménez, Cartas literarias..., pág. 255. 
los poetas más jóvenes entonces, considerándose traicionado por ellos, y su decisión irrevocable explícita en marzo de $1934^{19}$, aunque confidencialmente continuaría criticando a Jorge Guillén («un farsante en todo, vida literaria y vida social»), Pedro Salinas ("esa sufragista encaprichada») ${ }^{20} \mathrm{o}$ "los versos del estirpado [sic] Vicente Aleixandre» ${ }^{21}$, «un existencialista de butaca permanente» ${ }^{22}$. Cuando concluye la guerra civil, es precisamente Gerardo Diego uno de sus primeros corresponsales literarios en la Espańa del interior, además, por supuesto, del fiel Juan Guerrero. A él le escribe en enero de 1941, a la recepción en Coral Gables de Ángeles de Compostela (Barcelona, Biblioteca Patria, 1940), y le confiesa su «alegría» y la necesidad, «olvidado lo menor y lo peor», de que le hable de Espańa: «Escríbame, hábleme de España» ${ }^{23}$. A él le dedicará también Espacio, cuando el poema aparezca con sus «3 estrofas», en edición definitiva, en la revista Poesía Española, en abril de $1954^{24}$ :

A Gerardo Diego, que fué [sic] justo al situar, como crítico, el «Fragmento primero» de este «Espacio», cuando se publicó, hace [algunos, tachado] años, en Méjico. Con agradecimiento lírico por la constante honradez de sus reacciones ${ }^{25}$.

19. Vid. «Entrevista telefónica a J. R. Jiménez de M. Pérez Ferrero», Heraldo de Madrid, 22-III-1934 y Juan Ramón Jiménez, "Poesía en soledad», Heraldo de Madrid, 29-III-1934, recogidos ahora en Gabriele Morelli, Historia y recepción de la "Antología" poética de Gerardo Diego, Valencia, Pre-Textos, 1997, págs. 326-329. Asimismo pueden verse las cartas de Gerardo Diego a Jorge Guillén, Ibid., págs. 224-225. Puede verse también la «Introducción» de Gabriele Morelli, Ibid., págs. 94-102. Vid. José Teruel, «Introducción» a Gerardo Diego, Poesía Española [Antologías], Madrid, Cátedra, 2007, págs. 61-62, y notas correspondientes en págs. 599-600. Juan Guerrero Ruiz, Juan Ramón de viva voz, ed. de Manuel Ruiz-Funes Fernández, Valencia, Pre-Textos, 1998-1999, vol. II, págs. 171, 172, 180, 182 y 187. Francisco Javier Díez de Revenga, «Juan Ramón Jiménez y Gerardo Diego. Historia de una lealtad», Pureza Canelo y Elena Diego, eds., El legado de Juan Ramón Jiménez en la poesía española contemporánea, Madrid, Devenir, 2007, págs. 74-80.

20. Juan Ramón Jiménez, Cartas literarias..., págs. 102 y 108.

21. Carta a José Hierro recogida en Luce López-Baralt, Entre libélulas y ríos de estrellas: José Hierro y el lenguaje de lo imposible, Madrid, Cátedra, 2002, pág. 307.

22. Juan Ramón Jiménez, «Respuesta concisa. A un mutilado auténtico», Orígenes. Revista de Arte y Literatura, vol. X, 1953, pág. 5.

23. Juan Ramón Jiménez, Cartas literarias..., pág. 204.

24. Poesía Española, n 28 , abril de 1954, págs. 1-11.

25. Juan Ramón Jiménez, Espacio (3 estrofas), edición facsímil del original enviado para su publicación en la revista Poesía Española, Santander, Fundación Gerardo Diego, 2007. 
Efectivamente, Gerardo Diego, a quien en su carta de enero de 1941 Juan Ramón le había dicho que "reacciona honrada y dignamente en los casos desagradables», había escrito palabras elogiosas sobre los fragmentos del poema publicados en 1943 y 1944 en la revista mexicana Cuadernos Americanos $^{26}$, en un artículo publicado por el poeta santanderino en la revista Alférez ${ }^{27}$, en 1948.

Junto a Gerardo Diego, otro de los primeros corresponsales literarios de Juan Ramón en España tras la guerra civil es Pablo Bilbao Arístegui, a quien el moguereño escribe en noviembre de 1939, en respuesta a otra carta suya de mayo de ese año por el caso del «saqueo» del archivo de su casa madrileña, en Padilla, $\mathrm{n}^{\circ}$ 38. Bilbao Arístegui y Jaime Delclaux, amigos y miembros del grupo literario bilbaíno "Alea», al que pertenecían entre otros Blas de Otero y Esteban Urkiaga («Lauaxeta»), habían visitado a Juan Ramón en Madrid, hacia finales de mayo de $1936^{28}$. Jaime Delclaux, declarado juanramoniano, como muchos de los miembros del grupo bilbaíno, con el que también se relaciona por esas fechas Gerardo Diego, morirá durante la contienda bélica y el moguereño tendrá noticia de ello en el exilio, a través de la correspondencia de Bilbao Arístegui, quien le envía también cartas y poemas del escritor fallecido. En 1941, los amigos bilbaínos de Delclaux publicarán su libro Ala fugitiva, del que Juan Ramón recibe puntualmente un ejemplar en Coral Gables. Respondiendo a una solicitud de Bilbao Arístegui, el poeta enviará el 25 de noviembre de 1941 su "Canción para Jaime» («Vienen alas por oriente»), incorporada con diversas variantes al proyecto de En el otro costado, a fin de que sirva de pórtico a la edición de Poesías (Antología) (Hispánica. Madrid, 1943), publicado en la colección que dirige el fiel Juan Guerrero ${ }^{29}$. Juan Ramón, al preparar para la editorial Losada su libro La estación total con las Canciones de la nueva luz, le anuncia a Pablo Bilbao, en carta remitida

26. Juan Ramón Jiménez, "Espacio (Una estrofa)», Cuadernos Americanos, XI, $\mathrm{n}^{\circ}$ 5, septiembre-octubre de 1943, págs. 191-205. Juan Ramón Jiménez, "Espacio (fragmento primero de la segunda estrofa). Cantada», Cuadernos Americanos, XVII, n ${ }^{\circ} 5$, septiembreoctubre de 1944, págs. 181-183. Las cartas del envío a Juan Larrea, como secretario de la revista, fechadas el 24 de julio de 1943 y el 21 de mayo de 1944, se encuentran en Cartas literarias..., págs. 74-76.

27. Gerardo Diego, «Nostalgia de Juan Ramón»...

28. He tratado el asunto en mi artículo «Bilbao bajo las bombas: tres calas en la formación de un grupo de escritores en Bilbao en el preludio de la guerra civil», Bidebarrieta. Revista de Humanidades y Ciencias Sociales de Bilbao, vol. XVIII, 2007 (Monográfico «70 ańos de la guerra civil: guerra, posguerra y memoria»), págs. 312-314.

29. El poema, con algunas variantes, se incorporará a En el otro costado, en Juan Ramón Jiménez, Lirica de una Atlántida, ed. Alfonso Alegre Heitzmann, Barcelona, Galaxia Gutenberg-Círculo de Lectores, 1999, págs. 73-74. 
el 22 de abril de 1945, la intención de colocar al frente del libro la siguiente dedicatoria: "A la memoria de Jaime Delclaux y a la vijilia de Pablo Bilbao Arístegui, con pensamiento acumulado». Efectivamente, así aparece el libro en 1946, en una muestra más de agradecimiento y de reconocimiento por parte del futuro premio Nobel.

Juan Guerrero sería también el responsable de la publicación en España del libro de Carlo Bo, La poesía con Juan Ramón Jiménez (Madrid, Hispánica, 1943), cuya edición original se había hecho en Italia dos años antes. El libro de Bo, prologado por José María Alfaro, suponía, a la espera de nuevos libros del poeta moguereño, la presentación en España de algunos de sus últimos poemas, seleccionados por Guerrero. "Contentémonos -escribía Gerardo Diego en 1948- con los anticipos que alguna revista o libro como el de Carlos Bono [sic, por Carlo Bo] ofrece de tarde en tarde» ${ }^{30}$. El lector de la Espańa interior tuvo ahí acceso a algunos textos, entre otros anteriores, sólo antes publicados en revistas del exilio o adelantados en Canción y en los Cuadernos juanramonianos, de La estación total ("Con las rosas», "Pájaro fiel» [Mirlo fiel»], "Mediodía» [ $\mathrm{Su}$ sitio fiel»], "Criatura afortunada»), En el otro costado ("Canto» ["Réquiem de vivos y muertos»]) o Romances de Coral Gables («La noche mejor», «Los árboles» [«Árboles hombres»] y «Navegante»). Estos textos ampliaban notablemente la lectura que pudiera hacerse del poeta desde la Segunda antolojía poética (1922) o Canción (1936), y, en cierto modo, contradecían la estrecha lectura purista que, al modo de Alfaro, pudiera hacerse de su obra, y apuntaban hacia esa "poesía humanísima» que entreveía Diego (el proceso de evolución "hacia adentro» señalado en la Segunda antolojía poética ${ }^{31}$ ) y buena parte de la poesía de posguerra.

Precisamente en el $\mathrm{n}^{\circ} 10$, correspondiente a febrero de 1944, de la revista Garcilaso, que, bajo la dirección de José García Nieto desde poco menos de un año atrás ${ }^{32}$, tutelaba José María Alfaro, iba a publicarse el último poema seleccionado por Guerrero en el libro mencionado, que sería la primera colaboración del poeta en una revista española: "Canto» («Cuando todos los siglos vuelven...»). Por esas mismas fechas, se reproducía en el n 5-6 (1944), número de homenaje a Vicente Aleixandre, de la valenciana Corcel, dirigida por Ricardo Juan Blasco, pero con la colaboración de José Hierro y José Luis Hidalgo, entre otros, un texto sobre el poeta del 27 que el moguereño

30. Gerardo Diego, «Nostalgia de Juan Ramón»..., p. 33.

31. Gerardo Diego, "Juan Ramón Jiménez: Segunda antolojía poética (1898-1918)», Revista de Occidente, n 3, 1923. Recogido en Obras completas..., t. VIII, pág. 27.

32. Vid. José María Martínez Cachero, La revista de poesía "Garcilaso» (1943-1946) y sus alrededores, Madrid, Devenir, 2005, passim. 
había escrito en 1930, y que se había publicado en las revistas Presente y Héroe, antes de la guerra civil, recogiéndose en la reciente edición argentina de Españoles de tres mundos (1942): «Confundo a Vicente Aleixandre con un torreón almagra...». Con el apoyo de Joaquín Reguera Sevilla, había comenzado a publicarse en Santander en abril de 1944, de la mano de Pedro Gómez Cantolla, Proel, una revista de poesía muy próxima a los presupuestos estéticos de Corcel, en la que, con colaboraciones de Hierro, Hidalgo y Julio Maruri, pronto se abriría una línea poética neorromántica, que abocaría finalmente a la poesía existencial y comprometida en la que cuajaría la «quinta del $42 »^{33}$. Fiel a la devoción juanramoniana de Hidalgo y Hierro, sobre todo, pero también de Ricardo Gullón, que pronto se incorporaría a las páginas de crítica, el no 15-16-17 (junio-julio-agosto de 1945) de Proel se abriría con otro de los poemas adelantados en el libro de Carlo Bo, "Mediodía» [ $\mathrm{Su}$ sitio fiel»] («Las nubes y los árboles se funden...»), publicado ya en El Sol (24-XI-1935) que se incorporaría en 1946 a La estación total. En el primer número de la revista barcelonesa Leonardo, publicado en abril de 1945, apareció por primera vez en España una parte del «Fragmento tercero» de Espacio, en verso, el titulado "Cantada» («No luce oro la hoja seca, canta oro...»), que ya se había publicado con algunas variantes en julio del año anterior en la etapa mexicana de Litoral, adelantándose en casi una década a la que sería su edición definitiva ${ }^{34}$. «Espacio. (Fundición)» («Prendí fuego a los labios de la rosa...») se publicaría en el $n^{\circ} 40$ (1949) de la revista leonesa Espadaña, uno de los elementos más combativos de la época, en que convivirían las corrientes derivadas de la rehumanización (el neorromanticismo, el tremendismo y la poesía existencial), con los primeros atisbos de una poesía decididamente comprometida social y políticamente; el poema, que había sido publicado el año anterior en Los Anales de Buenos Aires, se había pensado como una de las partes que iban a incorporarse al «Fragmento tercero» de Espacio, pero finalmente se incluyó en Una colina meridiana. Ese mismo año habían comenzado a darse a conocer en diversas revistas españolas algunos de los poemas del nuevo libro de Juan Ramón, que aparecería en Argentina: Animal de fondo (Buenos Aires, Pleamar, 1949). En el n 33 (septiembre de 1948) de Ínsula, ya se había publicado «La forma que me queda» («Entre la arboladura serena y la alta nube...»), pero en el $n^{\circ} 38$ (febrero de 1949) se adelantan ya varios poemas del nuevo libro («Al centro rayeante», «Lo májico esencial nombrado» y «En lo mejor que tengo»); en el

33. Vid. Emilio E. de Torre-Gracia, Proel (Santander, 1944-1950): revista de poesía / revista de compromiso, Madrid, Verbum, 1994, págs. 42 y ss.

34. Alfonso Alegre-Heitzmann, «Génesis, contexto y versión final de Espacio: algunas consideraciones», Cuadernos Adrede, n 4, 2007, págs. 23-26. 
$n^{\circ} 46$ (octubre de 1949) se reproducirá «En igualdad segura de espresión» y en el $n^{\circ} 49$ (enero de 1950) se incluirán "Soy animal de fondo» y la prosa «El español perdido", perteneciente a varios proyectos juanramonianos (Guerra en España, Vida y muerte de la mamá pura). La poesía reciente tendría una espléndida acogida desde las páginas de Insula, con artículos de Alejandro Busnioceanu («La poesía nueva de Juan Ramón Jiménez», $\mathrm{n}^{\circ}$ 37, enero de 1949) y Ricardo Gullón («Un canto para la poesía», $n^{\circ} 48$, diciembre de 1949). Prueba de la buena relación que el poeta mantiene con la revista madrileña, y especialmente con su secretario, José Luis Cano, es la carta que el moguereño le remite el 10 de octubre de 1949 prometiéndole el envío, antes de enero siguiente, de "dos libros inéditos míos: Lírica de una Atlántida y Hacia otra desnudez; uno para 'Adonais' y otro para 'Ínsula'. Usted puede situarlos a su gusto" " 35 . Incluso a comienzos de 1953 se preparará un homenaje al poeta en la revista madrileña que el propio Juan Ramón prohíbe en carta a Enrique Canito ${ }^{36}$. Otras revistas, como la madrileña Finisterre (noviembre de 1948), la alicantina Verbo ( $\mathrm{n}^{\circ} 15$, marzo-abril de 1949), la santanderina La Isla de los Ratones $\left(\mathrm{n}^{\circ} 9,1950\right)$ o la madrileña Raiz $\left(\mathrm{n}^{\circ} 6\right.$, noviembre de 1949) presentan textos de En el otro costado ("Con lo altivo intacto"), Una colina meridiana («En su copa de gloria») y Animal de fondo ( SSoy animal de fondo», "Con la cruz del Sur», "Con mi mitad allí» y «Riomar-desierto») ${ }^{37}$. Incluso la postista La Cerbatana recogería en su único número de 1945 el testigo del moguereńo con una cancioncilla de 1909 («Una y él»), recogida en la edición de 1936 de Canción. La relación de Juan Ramón con las revistas poéticas españolas continuaría, como se verá más adelante, en la década siguiente, con las andaluzas Platero, Caracola, Al-Motamid y Ketama, o con las madrileñas Poesía Española, Índice y Correo literario, además de la constante colaboración en Ínsula. Así pues, más allá de la relación epistolar que Juan Ramón mantiene con muchos de los más destacados poetas de la posguerra en España (José Hierro, Ángela Figuera, Ramón de Garciasol, José García Nieto, José Luis Cano, etc.), los lectores interesados podían tener, a través de las revistas poéticas publicadas en el interior, cumplida noticia de la evolución y producción poética que venía experimentando el moguereño en su obra del exilio.

35. Juan Ramón Jiménez, Cartas literarias..., pág. 193.

36. Ibid., págs. 251-252.

37. Sobre la relación de Juan Ramón Jiménez con la santanderina La Isla de los Ratones, vid. Ricardo Gullón, "Juan Ramón Jiménez y La Isla de los Ratones", La Isla de los Ratones. Poesía española del medio siglo, Santander, Obra Social y Cultural de Caja Cantabria, 1998, págs. 153-176. 
Si un libro quiebra el panorama poético de posguerra ${ }^{38}$ éste es, sin duda, más allá de Sombra del Paraíso, de Vicente Aleixandre, Hijos de la ira, de Dámaso Alonso. Él mismo se define, en un significativo artículo publicado en 1952, como uno de los baluartes de una nueva corriente poética de carácter "desarraigado», que hunde sus raíces en los prolegómenos del conflicto civil: "Para otros, el mundo nos es un caos y una angustia, y la poesía una frenética búsqueda de ordenación y de ancla ${ }^{39}$. Dámaso Alonso había sido fiel al influjo poético juanramoniano y de ello había quedado testimonio en la Antología de 1932 de Gerardo Diego, donde se iniciaba su selección poética con el soneto "¿Cómo era?», con cita de «Retorno fugaz», perteneciente a Sonetos espirituales, una recreación-homenaje del texto juanramoniano ${ }^{40}$. En Hijos de la ira, uno de los poemas más antiguos del libro, "Cosa», anterior a la guerra civil ${ }^{41}$, aparece ahora encabezado por un verso que procede de "Criatura afortunada» («Rompes... el ondear del aire»), perteneciente a La estación total, pero que ya había sido incluido en uno de los Cuadernos juanramonianos. Es significativo cómo éste, de Dámaso Alonso, uno de los poemas del libro sobre la indagación del ser, sobre la voluntad de conocimiento y el fracaso, adquiere sentido pleno en su diálogo con el poema juanramoniano que es un canto a la plenitud, a la realización plena de una temporalidad sin límites en la «estación total». La "criatura afortunada» que es "presencia casual perpetua» en el poema del moguereño, se transforma en el poema de Hijos de la ira en una «bestezuela de sombra» que sólo otorga su «dura negativa de alimaña»; frente a la plenitud del poema juanramoniano, la frustración del nuevo texto; frente a la percepción de un ideal paradisíaco en «una eternidad de eternidades», la pérdida del paraíso (uno de los temas recurrentes en la poesía de la primera posguerra) y la caída en el tiempo: "Cuando la mano intenta poseerte, / siente la piel tus límites». Pero el poema de Dámaso Alonso parece construirse como un contrafactum del texto juanramoniano, e ilumina así una de las perspectivas en que penetra el influjo del poeta moguereño en la poesía de posguerra: los elementos

38. Como «un auténtico golpe de azadón removiendo todo el terreno» lo definiría Blas de Otero en el Homenaje universitario a Dámaso Alonso, Madrid, Gredos, 1970.

39. Dámaso Alonso, «Poesía arraigada y poesía desarraigada», Poetas españoles contemporáneos, Madrid, Gredos, 1965, 3a ed. (1ª ed.: 1952), p. 349.

40. La cita desapareció, por motivos editoriales, en la segunda edición. Sobre este asunto, vid. Dámaso Alonso, "Vida y obra», Antología de nuestro monstruoso mundo, ed. del autor, Madrid, Cátedra, 1985, pág. 19, nota. Juan Guerrero Ruiz, Juan Ramón de viva voz..., vol. II, pág. 304. Gabriele Morelli, Op. cit., págs. 97-99. Gerardo Diego, Poesía española..., pág. 267, nota.

41. Vid. Dámaso Alonso, Hijos de la ira, ed. Miguel J. Flys, Madrid, Castalia, 1986, pág. 93. 
naturales quedan subvertidos, negados («Rajas el viento, / partes la niebla, / hiendes el agua»); el colorido de la criatura afortunada («azul, oro, plata y verde») queda desvalorizado ("ya teñida de ti: verde, amarilla, / [...], gris, roja, plata»); el triunfo de la plenitud («No hay temor en tu gloria») apunta a la constatación del fracaso («vencida», «inaprensible»).

No cabe duda de que buena parte de la poesía de posguerra percibe en Juan Ramón el modelo de una cosmovisión que se ha venido abajo con los acontecimientos históricos, pero también percibe la esencia temporal y consecuentemente existencial que subyace en la poesía del moguereńo y que va a hacer aflorar la percepción humana («humanísima»), su profundidad gnoseológica y el modelo ético que se transparenta en sus versos (recuérdese la propuesta social de «El trabajo gustoso»). No en vano, uno de los poetas más juanramonianos de la posguerra, Blas de Otero, pondrá en 1948 bajo la advocación del poeta sus primeros "Poemas para el hombre» ${ }^{42}$, evocando y transformando los versos finales de la poética de Eternidades: «Oh pasión de mi vida, poesía / humana, mía para siempre!». La desnudez juanramoniana queda así suplida por la humanidad oteriana, pero la entrega a la "pasión» poética es semejante y la aceptación del magisterio de Juan Ramón revela la dimensión humana, la ética, que se transparenta a través de esa desnudez estética, como modelo expresivo pero también conceptual, que ambos poetas persiguen. No se trata, por lo tanto, de una crítica a la poética juanramoniana, sino de una lectura diferente desde los nuevos presupuestos que ésta propugna. El poeta bilbaíno, en un nuevo giro, dedicaría su primer libro, Ángel fieramente bumano (1950), «a la inmensa mayoría» (que sería también el título del poema inicial de Pido la paz y la palabra, 1955), subvirtiendo la dedicatoria "a la inmensa minoría» que el andaluz había colocado en 1923 al frente de Poesía y Belleza ${ }^{43}$. No cabe ver, de nuevo, una crítica al modelo ético-estético juanramoniano, sino más bien un homenaje que persigue la actualización histórica del modelo institucionista en que se funda la perspectiva del poeta andaluz y que hereda la visión más progresista

42. Blas de Otero, «Poemas para el hombre», Egan, n 1, 1948, págs. 3-9.

43. En carta a José Luis Cano aclarará el concepto que, según declara allí, provendría de una carta de Antonio Marichalar: «Cuando yo empecé a poner al frente de mis libros 'a la minoría siempre', estaba pensando que la minoría se encuentra en todas partes, en el pueblo 'cultivado' por sí mismo, tanto o más que en el hombre 'culturado' en los libros de las ciudades. [...] Entonces acepté la dedicatoria que por una indudable coincidencia de crítica Antonio Marichalar me había escrito en una carta: 'a la inmensa minoría'. // Yo creo que en mi escritura poética, verso y prosa, está mi emoción dirijida instintivamente, es claro, a todos; que todos, nińos, jente del pueblo y del campo, jente internacional puede encontrar lo suyo en ella y esto es para mí lo mejor de mi poesía» (Cartas literarias..., pág. 194). 
de la intelectualidad bajo el franquismo ${ }^{44}$. No se puede y no se quiere obviar la presencia juanramoniana en la escritura de posguerra (al fin y al cabo, como declarará José Hierro años más tarde, «estamos hablando en lenguaje de Juan Ramón» ${ }^{45}$ ) y, consecuentemente, su modelo, asumido como el de la poesía de Rubén Darío, la de Antonio Machado o los poetas más destacados del 27 , se toma como pauta para una necesaria actualización histórica, que el propio poeta, por su parte, lleva a cabo en el exilio. Gabriel Celaya lo expresa de modo meridiano por esas fechas, al señalar la influencia decisiva que Juan Ramón tuvo en los años de formación de su generación: «arrancando del modernismo había llegado a una poesía desnuda del mejor estilo» ${ }^{46}$. Juan Ramón resultaba ser el enlace necesario con la poesía de Bécquer y la estela neo-romántica que se extendería en los años previos e inmediatamente posteriores a la guerra.

Si repasamos la Antología consultada de la joven poesía española (1952) ${ }^{47}$, que nace en cierto modo como respuesta al modelo antológico establecido por Gerardo Diego en 1932-1934, veremos que el nombre de Juan Ramón Jiménez apenas aparece mencionado por alguno de los antologados (tan sólo lo menciona Eugenio de Nora, en un repaso histórico), ni se le dedica ningún poema; la presencia poética próxima más importante en las notas que redactan los antologados es la del «gran Vicente Aleixandre». Sin embargo, la poética de Juan Ramón subyace en buena parte de las formulaciones que hacen los jóvenes autores, para corregirla, transformarla o negarla, lo que indica que su magisterio resulta ineludible para los nuevos poetas, como reconoce explícitamente Eugenio de Nora: «Nuestros maestros, los míos, han sido poetas puros, versificadores de cuarto cerrado, de temas asépticos y de inmensa minoría ${ }^{48}$. Gabriel Celaya alude directamente a los conceptos del purismo juanramoniano, para negarlos: «Un poema es una integración y no ese residuo que queda cuando en nombre de lo puro, lo eterno, o lo bello, se practica un sistema de exclusiones»; «Nuestros hermanos mayores

44. Vid. Aurora de Albornoz, "Juan Ramón Jiménez o la poesía en sucesión» en Juan Ramón Jiménez, Nueva antolojía, ed. Aurora de Albornoz, Barcelona, Península, 1973, págs. 13-14. Aurora de Albornoz, «Blas de Otero, hoy, mañana», Ínsula, n 392-393, julio-agosto de 1979 , p. 6.

45. Víctor Márquez Reviriego, "Conversación con José Hierro: Casi cuanto sé de mí», Triunfo, año XXXV, n ${ }^{13}, 1$ de noviembre de 1981, pág. 48. Unos años antes, en la misma revista, Hierro declararía: «Puede decirse que soy juanramonísimo» (Eduardo G. Rico, «José Hierro: juanramonísimo", Triunfo, año XXV, n 432, 12 de septiembre de 1970, pág. 36).

46. Gabriel Celaya, «Veinte años de poesía», Egan, n 2, 1948, págs. 27-28.

47. Fransico Ribes, Antología consultada de la joven poesía española, Valencia, Mares dist., 1952.

48. Eugenio de Nora, «Respuestas muy incompletas», Ibid., pág. 149. 
escribían para la inmensa minoría. Pero hoy estamos ante un nuevo tipo de receptores espectantes [sic]» ${ }^{49}$. José Hierro declara rotundamente: «detesto la torre de marfil ${ }^{50}$. Y en esa misma línea parecen insertarse poemas recogidos en aquella antología como "Para un esteta», de José Hierro, o "A la inmensa mayoría», de Blas de Otero. En cambio, nada más distante de la realidad que ese ataque a la poesía juanramoniana, puesto que su obra dibuja la pauta sobre la que se va escribir una parte importante de la poesía de posguerra.

$\mathrm{Y}$ es que buena parte de la poesía de posguerra coincide con la juanramoniana en un buen número de temas semejantes, pero también en formas comunes (la canción y el collage, las yuxtaposiciones, los metros, etc.) y en la búsqueda de una desnudez expresiva, que se manifiesta como un radical antirretoricismo, fundado en aquella «sencillez sintética» que caracterizaba, según las notas de 1922, la «tradición popular del arte» en que Juan Ramón trataba de incardinar su producción poética ${ }^{51}$. Esa «sencillez» que hace que en la poesía "desnuda» desaparezca la forma «dejando existir sólo el contenido» es la que, sin duda, trata de definir Blas de Otero en su obra a partir de Pido la paz y la palabra (1955), tal como le indica en 1968 a Antonio Núñez al hablar de «una sencillez de vuelta» en su última poesía ${ }^{52}$; esa «sencillez de vuelta», tan próxima a la juanramoniana, será la que busque el vasco en su última etapa de poesíabierta ${ }^{53}$. Se trata, siguiendo el modelo de su admirado Juan Ramón, de la búsqueda de una expresión más condensada, caracterizada, como declarará en la Antología consultada, por un proceso de «contención», «eliminación», «búsqueda» $\mathrm{y}$ «espera» ${ }^{54}$. Es, sin duda, esa misma sencillez la que define la "palabra transparente»" ${ }^{55}$ que reclama José Hierro en 1953 para su poesía, en un texto en el que resuenan los ecos juanramonianos: «La palabra no ha de verse, no ha de ser motivo de complacencias. [...] La perfección de la palabra reside en la forma [...] y en la transparencia» ${ }^{56}$. El poeta santanderino venía apuntando semejante concepción desde algunos años antes, y si en 1950 había escrito que «la

49. Gabriel Celaya, «Poesía eres tú», Ibid., págs. 44 y 46.

50. José Hierro, «Algo sobre poesía, poética y poetas», Ibid., pág. 106.

51. Juan Ramón Jiménez, Segunda antolojía poética, Madrid, Calpe, 1922, pág. 322.

52. Antonio Núñez, «Encuentro con Blas de Otero», Ínsula, n² 259, junio de 1968, pág. 3 .

53. Vid. Laura R. Scarano, «La poesíabierta de Blas de Otero: hacia un nuevo concepto de escritura», Letras de Deusto, n 63, 1994, págs. 217-228.

54. Blas de Otero, "Y así quisiera yo la obra», Antología consultada..., pág. 180.

55. Vid. Gonzalo Corona Marzol, Realidad vital y realidad poética. (Poesía y poética de José Hierro), Zaragoza, Prensas Universitarias, 1991, págs. 279-281.

56. José Hierro, "Poesía y poética», Arbor, tomo XXIV, n 85-88, enero-abril de 1953, pág. 32. 
forma es el vaso transparente que encierra la idea " ${ }^{57}$, en su poética para la Antología consultada de 1952 había sido más esclarecedor: «La palabra, en cuanto letra, [...] [es] una vasija de finísimo cristal a cuyo través se ve el licor de su significado" ${ }^{58}$. Más allá de que quizás la imagen del «cristal» proceda de Paul Valéry (La Jeune Parque, 1917: «Passe entre mes regards sans briser leur absence, / Comme passe le verre au travers du soleil») a través de la referencia que Sartre hace en ¿Qué es la literatura? (1948) («Hay prosa cuando, para hablar como Valéry, la palabra pasa a través de nuestra mirada como el sol a través del cristal») ${ }^{59}$, lo cierto es que las palabras de Hierro parecen hacerse eco directo de la concepción juanramoniana expuesta en 1922 y de su expresión meridiana, quizás inspirada también por el poeta francés, en su conferencia de 1948 "Poesía cerrada y poesía abierta»: «la forma poética perfecta sería, para mí, la que pudiera tener el espíritu si el cuerpo se le cayera como un molde; el agua de un vaso, si el cristal se pudiera separar ${ }^{60}$. Y más evidente resulta el eco juanramoniano en las siguientes palabras con las que Hierro define la poesía en un texto que ha de datar de esos años: «La poesía es la distancia más corta entre dos espíritus, absoluta desnudez» ${ }^{61}$. La «desnudez» del estilo que solicita José Hierro, tiene, por lo tanto, mucho que ver con la "poesía desnuda» que reclamaba Juan Ramón en Eternidades, pero no contradice en absoluto la esencia humana que solicita para su obra, la del hombre dividido característico de la "Quinta del $42 »^{62}$. El propio poeta se lo confiesa al andaluz en el exilio en una carta fechada el 4 de diciembre de 1949:

Hoy no hay poesía en España. Usted se ha llevado toda la vida hablando de desnudez de la poesía y ha logrado acertar con un corazón esencial, pero los demás han tomado el rábano por las hojas, han derrochado su herencia. [...] Hemos perdido veinte años de poesía. [...] La poesía de hoy [...] es desordenada, confusa y excesivamente verbosa, porque le falta serenidad y mirada clara y la eterna juventud, cuyo secreto usted tiene y que sirve para no acortezarse ${ }^{63}$.

57. José Hierro, «Actualidad de Rubén Darío», Alerta, 20-IV-1950, pág. 3.

58. José Hierro, «Algo sobre poesía, poética y poetas», Antología consultada..., pág. 101.

59. Jean-Paul Sartre, ¿Qué es la literatura?, Buenos Aires, Losada, 1950, pág. 54.

60. Juan Ramón Jiménez, «Poesía cerrada y poesía abierta», El trabajo gustoso. (Conferencias), ed. Francisco Grafias, México, Aguilar, 1961, pág. 90.

61. José Hierro, "Con la poesía a vueltas», Guardados en sombra. Textos de la prehistoria literaria de José Hierro, ed. Luce López-Baralt, Madrid, Cátedra, 2002, pág. 50.

62. Vid. Gonzalo Corona Marzol, Op. cit., págs. 131-135.

63. «Epistolario entre José Hierro y Juan Ramón Jiménez», reproducido por Luce 
La «desnudez», como la «sencillez de vuelta» o la "transparencia» se identifican con la «exactitud» juanramoniana, con la "perfección» que exigía el andaluz, pero también con la conciencia creativa y con la capacidad comunicativa de la palabra sencilla, alejada del «descuido callejero de la forma». Esa sencillez esencial, esa transparencia de la forma, esa desnudez expresiva, esa poesía "seca y desnuda, pobre de imágenes», que reclama para sí José Hierro ${ }^{64}$, será lo que busque el antirretoricismo de la poesía social y testimonial en los primeros años cincuenta; será también el signo que marque el giro hacia un nuevo clasicismo expresivo en algunos de los poetas más jóvenes en torno al comienzo de la nueva década ${ }^{65}$. ¿Acaso no se encontraría ahí la concepción comunicativa celayana de la poesía como un "cortocircuito [que] quema y deja en nada la materia verbal» ${ }^{66}$ ?

El magisterio de Juan Ramón en la formación de los poetas de posguerra es algo evidente si se leen con atención sus primeros poemas y libros. Si bien Gabriel Celaya ha insistido en la presencia de una cosmovisión surrealista en sus primeros libros ${ }^{67}$, es indudable la huella de la presencia de la poesía de Juan Ramón Jiménez, junto a la de Guillén y Salinas, en Marea de silencio (1935) y La soledad cerrada $(1936)^{68}$. No es difícil entresacar entre los primeros poemarios del autor donostiarra versos que denotan una clara influencia juanramoniana, directa o quizás a través de la lectura del Cántico de Guillén:

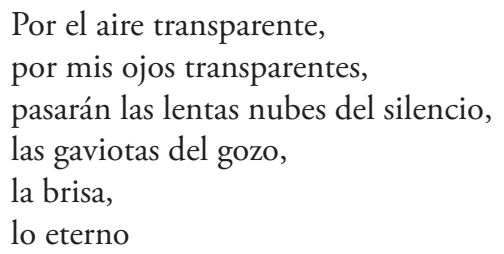

López-Baralt, Entre libélulas y ríos de estrellas: José Hierro y el lenguaje de lo imposible, Madrid, Cátedra, 2002, pág. 288.

64. José Hierro, "Prólogo», Poesías completas (1944-1962), Madrid, Ed. Giner, 1962, pág. 1962.

65. Vid. Eugenio de Nora, "Espadaña, 30 años después», Espadaña, ed. facsímil, León, Espadaña Editorial, 1978, pág. XVII.

66. Gabriel Celaya, «Poesía eres tú», Antología consultada..., pág. 45.

67. Gabriel Celaya, Reflexiones sobre mi poesía, Madrid, Universidad Autónoma de Madrid, 1987, pág. 12.

68. José Ángel Ascunce, «Introducción biográfica y crítica», Gabriel Celaya, Trayectoria poética. Antología, ed. José Ángel Ascunce, Madrid, Castalia, 1993, págs. 29-35. Vid. Juan Cano Ballesta, Op. cit., pág. 252-254. Ángel González, «Intertextualidad e interdiscursividad en la poesía de Gabriel Celaya», La poesía y sus circunstancias, ed. José Luis García Martín, Barcelona, Seix Barral, 2005, págs. 324-325. 
El mar de puro ser se está quedando inerte.

¡Ser mar! ¡Ser sólo mar!

La eternidad del mar enfrente

El cielo es una música quieta.

El mar absorto,

plano,

de tan callado, piensa

Pero yo sé de un instante sin ayer ni mañana en que de pronto todo parece detenerse, instante que revela lo eterno de un presente que escapó a ese palpitar de nostalgias a esperanzas.

Marea de silencio muestra, sin duda, las huellas más marcadas del modelo purista impuesto por Juan Ramón: metro breve, rima asonantada, cierto conceptualismo, léxico característico («mar», «eterno», «transparente»), esencialidad, escasa adjetivación, etc. Pero también, recursos temáticos: búsqueda de plenitud, aspiración a lo eterno, contemplación, abstracción, etc. Sin embargo, comienza a aparecer muy pronto, quizás ya en La soledad cerrada, esa visión escindida característica de la poesía posterior, que revela la contemplación de la plenitud y la imposibilidad de vivir en ella y que se hace patente en "Quién me habita», un poema esencial para comprender la posterior evolución de Celaya. Pero quizá sobreviva la presencia juanramoniana en la poesía del donostiarra más allá de estos primeros ecos, por ejemplo en la concepción de una transparencia y desnudez que ha de caracterizar buena parte de la comunicabilidad en la escritura de Juan de Leceta ${ }^{69}$. $\mathrm{O}$, más aún, en la misma concepción de la poesía como un modo de acción («quisiera con sus versos lograr, no la belleza, / sino la acción que pueden y deben los poetas / promover con sus versos de conmovida urgencia», leemos en «Vivir para ver»), como un instrumento de transformación social, como un «arma cargada de futuro»:

Son palabras $[\ldots]$.

Son lo más necesario: lo que tiene nombre.

Son gritos en el cielo, y en la tierra, son actos.

69. Ángel González, «La obra poética de Gabriel Celaya», Ibid., págs. 304-305. 
Visto desde esta perspectiva, no hay tanta distancia entre la acción que instaura la poesía "como un instrumento, entre nosotros, para transformar el mundo ${ }^{70}$ y el acto inaugural y genesíaco que, con ecos del Fausto de Goethe, lleva a cabo Juan Ramón al formular su poética en Eternidades («No sé con qué decirlo, / porque aún no está hecha / mi palabra») y que concluirá en la exaltación definitiva de Animal de fondo, como punto de llegada de la «búsqueda metafísica del sentido de las cosas» ${ }^{71}$ en la palabra poética que el moguereño lleva a cabo a lo largo de toda su obra; al fin y al cabo, ya había escrito en 1936: «Levantando la poesía del pueblo se habrá diseminado la mejor semilla social política» ${ }^{72}$. Ambas concepciones quizás sean deudoras de un idealismo lingüístico de raíz heideggeriana o quizás de un giro lingüístico que, como en la concepción austiniana, dota al lenguaje de una capacidad performativa. En cualquier caso, la reflexión metapoética que caracteriza buena parte de la escritura de la poesía social en los años cincuenta, va a encontrar ahí el engarce con la reflexión metapoética que atraviesa de cabo a rabo, pero especialmente desde Diario de un poeta reciencasado, la poesía de Juan Ramón Jiménez. Si, como señaló Ricardo Gullón, «la poesía es el gran tema de Juan Ramón» ${ }^{73}$, no cabe duda de que la reflexión sobre la escritura que ello implica va a caracterizar su obra y también la de aquellos poetas que comienzan a preocuparse por la potencialidad actuativa de la palabra poética en la transformación de un mundo por hacer.

José Hierro siempre se declaró deudor de tres grandes poetas: Rubén Darío, Juan Ramón Jiménez y Gerardo Diego. «Pienso que en los tres poetas que he citado aprendí lo poco o mucho que del oficio poético sés ${ }^{74}$. La lectura de Juan Ramón, como la de Versos humanos, de Gerardo Diego, se realiza en 1935, y la huella que deja en el poeta es indeleble. El eco de Juan Ramón es indudable en Tierra sin nosotros (1947), tal como testimonian unos versos de «Primavera total», perteneciente a Poesía, que, como epígrafe, abren el poema «Sólo la muerte»:

70. Gabriel Celaya, «Poesía eres tú», Op. cit., pág. 44.

71. Carlos León Liquete, "Introducción», Juan Ramón Jiménez, Animal de fondo, ed. Carlos León Liquete, Obra poética, coord. Javier Blasco y Teresa Gómez Trueba, Madrid, Espasa, 2005, tomo I, vol. II, pág. 1124. Vid. Vicente Gallego, "Juan Ramón: creador de mundos y de dioses», Juan Ramón Jiménez, Obras de Juan Ramón Jiménez. Animal de fondo (1949), Madrid, Visor, 2007, págs. 8 y ss.

72. Juan Ramón Jiménez, «El trabajo gustoso», El trabajo..., pag. 31.

73. Ricardo Gullón, Estudios sobre Juan Ramón Jiménez, Buenos Aires, Losada, 1960, pág. 185.

74. José Hierro, Poesía del momento, Madrid, Afrodisio Aguado, 1957, pág. 9. 


\section{¡Madre mía, tierra; \\ sé tú siempre joven, \\ y que yo me muera!}

El libro se coloca desde el comienzo bajo la advocación del poeta, cuya obra deja huellas evidentes en "Ciudad a lo lejos», «Recuerdo del mar», «Llegada al mar» ("Cuando salí de ti, a mí mismo / me prometí que volvería»), "Cumbre» o en la potencialidad simbólica de "Gaviota», "Agua», "Olas», etc., o incluso en el tono simbolista que se percibe en «Vino»; «Pasado» se establece a partir de un desdoblamiento del sujeto poético que recuerda al Juan Ramón de "¿Soy yo quien anda, esta noche...», de Jardines lejanos, y que coincide con Espacio; "Alma dormida» parece intertextualizar "Viento negro, luna blanca» ${ }^{75}$. De hecho, puede verse el libro como un diálogo implícito con la cosmovisión purista juanramoniana, que supone a su vez un desdoblamiento del sujeto poético que dialoga consigo mismo, que atraviesa desde «Entonces» hasta «Tierra sin nosotros» o «Ya se han roto las ataduras» y que deja un testimonio esclarecedor de la conciencia generacional en «Generación»:

\section{Porque nacimos bajo el signo del cerebro. Pero ya todo se vino a tierra una mańana.}

Tierra sin nosotros, como buena parte de la poesía posterior de José Hierro, es la narración de la expulsión del paraíso, de la caída en el tiempo, de la pérdida de un mundo, de la unidad paradisíaca, y del lenguaje que le daba sentido; un mundo de plenitud que ahora se contempla desde la realidad escindida del hombre arrojado a la Historia, expulsado del "presente absoluto», del «instante absoluto» al que, como Juan Ramón, aspira (y que le llevará a los diferentes juegos de yuxtaposiciones espacio-temporales), que verá posteriormente las palabras, «las palabras difíciles», el «Nombrar perecedero», la evocación del «nombre exacto», de "las palabras / de diamante purísimo», como el último testimonio de la expulsión de un lenguaje inasequible, que busca la fusión imposible de lo eterno y lo temporal en una palabra trascendente y perecedera (testimonial, histórica) al mismo tiempo. La conciencia del tiempo, que vertebra la poética de José Hierro y que lo enlaza con la poética juanramoniana ${ }^{76}$, se manifiesta así como una conciencia de la pérdida del

75. José María Naharro-Calderón, Entre el exilio y el interior: el «entresiglo» y Juan Ramón Jiménez, Barcelona, Anthropos, 1994, págs. 258-259.

76. Manuel Ángel Vázquez Medel, «Compromiso y estética: Juan Ramón Jiménez y José Hierro», Martín Muelas Herraiz y Juan José Gómez Brihuega, eds., Leer y entender la poesía: José Hierro, Cuenca, Universidad de Castilla-La Mancha, 2001, págs. 71-85. 
lenguaje, que también caracteriza al moguereño. Más que nostalgia de un mundo, lo que hay en los primeros libros de Hierro es la nostalgia de un lenguaje que ya no puede decirse sino a través del silencio, puesto que las palabras han subvertido sus valores; constatación del hueco, del vacío, que existe entre lo que esas palabras dicen y lo que significaron. El diálogo con el Juan Ramón de «iIntelijencia, dame / el nombre exacto de las cosas!», pero también con el poeta puro que lleva en sí mismo, se pone de manifiesto así en los siguientes versos de Con las piedras, con el viento... (1950):
Antes nombraba todas las cosas, como si ellas fueran mis creadoras, mi creación. [...]
Ahora digo: «Mar, monte, Árbol», como si fueran los olvidados, muertos de mi mundo encendido.

$\mathrm{O}$ en los siguientes "Versos pedidos», que puede leerse también, en cuanto que repaso de la propia evolución poética, como una réplica a «Vino, primero, pura...»:
No he podido
hallar la palabra exacta,
lograr el nombre preciso.

Es en ese contexto en el que debe insertarse la lectura de "Para un esteta», incluido en Quinta del 42 (1952) que, tal como ha venido señalándose desde José Olivio Jiménez y Aurora de Albornoz ${ }^{77}$, ha de leerse como un diálogo implícito del sujeto poético consigo mismo, en un juego de desdoblamiento, por el que la invectiva resulta doble: contra los esteticistas, pero también contra «el esteta que lleva uno dentro y que añora este tipo de poesía, pero que es consciente de que no la puede hacer en un determinado momento histórico» ${ }^{78}$.

77. José Olivio Jiménez, Cinco poetas del tiempo, Madrid, Ínsula, 1964, pág. 285. Aurora de Albornoz, "Introducción», José Hierro, Antología, Madrid, Visor, 1980, págs. 7-30. Aurora de Albornoz, José Hierro, Madrid-Gijón, Júcar, 1982, págs. 50-51. Gonzalo Corona Marzol, Op. cit., págs. 259-262. En los últimos años sólo Jorge Urrutia ha continuado sosteniendo la exclusiva referencia juanramoniana de ese poema: Jorge Urrutia, «Introducción», José Hierro, Quinta del 42, ed. Jorge Urrutia, Madrid, Biblioteca Nueva, 2001, págs. 23-30.

78. Declaraciones a Juan José Lanz, "José Hierro: Escribir poesía es siempre una frustración», 
Tú que hueles la flor de la bella palabra acaso no comprendas las mías sin aroma. Tú que buscas el agua que corre transparente no has de beber mis aguas rojas.

Lo has olvidado todo porque lo sabes todo.

Te crees dueño, no hermano menor de cuanto nombras. Y olvidas las raíces («Mi Obra», dices), olvidas que vida y muerte son tu obra.

Que el poema no iba dirigido contra Juan Ramón lo deja claro el propio Hierro en carta al andaluz, fechada el 21 de junio de 1953, donde le expone:

Hay en mi Quinta del 42 un «Prólogo a un esteta», que por decir «mi Obra», expresión que usted emplea, ha creído alguno que había sido escrito pensando en usted. No se dan cuenta que usted es poeta de obras completas y que el poetaesteta, de obra única, es, para mí, el pelmazo de Guillén [...]. El esteta es cualquier Guillén, cualquiera de esas cámaras sinfónicas para conservar la carne muerta ${ }^{79}$.

El «esteta» es aquel que se cree dueño de lo que nombra, y no su hermano menor ("Te crees dueño, no hermano menor de cuanto nombras»); hay en esos versos la nostalgia de nombrar lo innombrable, de hallar la palabra "exacta», pero también la conciencia de su imposibilidad. Prueba poética última de la admiración de Hierro por la obra de Juan Ramón será el «Cestillo de flores a J.R.J. y Z.C.A» que el santanderino publica en el homenaje que le rinde Poesía Española en diciembre de $1956^{80}$.

La admiración de Juan Ramón por Hierro queda explícita en la correspondencia que intercambian. «Le debo a una crónica radiada de Gerardo Diego -escribe Juan Ramón el 3 de noviembre de 1949-el segundo poema que conocí de usted; el año 47. Considero a usted uno de los pocos mejores entre los poetas jóvenes españoles actuales» ${ }^{81}$. La crónica radiada, escrita para el Panorama Poético Español en mayo de 1947 se reproducirá,

El Urogallo, $\mathrm{n}^{\circ}$ 57, febrero de 1991, pág. 15.

79. «Epistolario...», págs. 296-297.

80. El poema, que se publicará posteriormente en la "Corona poética en homenaje y honras a Juan Ramón Jiménez», aparecida en las páginas literarias del diario Arriba, 1-VI1958, se incluirá definitivamente en la tercera sección de Libro de las alucinaciones.

81. "Epistolario...", pág. 303. 
con algunas modificaciones, en $A B C$ el 16 de julio de 1947 con el título de "Un nuevo poeta» ${ }^{82}$; el poema que escuchó Juan Ramón en Maryland no era otro que "Canción de cuna para dormir a un preso", de Tierra sin nosotros. En su primera carta, en la que solicitaba un autógrafo del poeta y le remitía su primer libro, Hierro le comunicaba que su próximo hijo se llamaría Juan Ramón en honor al poeta. En respuesta, el andaluz le envía el poema «Las palomas» («Alrededor de la copa...») ${ }^{83}$ y el encargo, por persona interpuesta, de un regalo para el recién nacido. Juan Ramón colaborará en esos años en dos revistas muy próximas a Hierro, como son Proel y La Isla de los Ratones (allí publicará: "En su copa de gloria», n 9, 1950; "Romance son de mis venas», n 14, 1951; "Porque lo vi tan vacío», n²1-22, 1953; "Respiración total de nuestra entera gloria», «En un oasis eterno de lo interno» $\mathrm{y}$ "Un ascua de conciencia y de valor», $\left.\mathrm{n}^{\circ} 23,1954\right)$, y en algunos de los proyectos editoriales del grupo santanderino. Así, a petición del poeta, el moguereño le envía, en carta fechada en Río Piedras el 12 de mayo de 1953, dos romances, uno reciente («Por tanta cuesta de tierra») y uno «revivido» («Si la mar más grande fuera»), como "Pórtico» para su Antología poética (Santander, Hermanos Bedia, 1953). En la misma imprenta de los Hermanos Bedia, se publicarán ese año los Tres poemas (de "Dios deseado y deseante»), que recogería al ańo siguiente La Isla de los Ratones ${ }^{84}$. En una carta anterior, declaraba el poeta andaluz: "Acabo de leer su 'Episodio de primavera'. Si ud. sigue escribiendo poemas como éste, la poesía actual española se habrá salvado» ${ }^{85}$.

El ejemplo de José Hierro puede ser sintomático y característico de la presencia que tiene la poesía de Juan Ramón Jiménez en los poetas de posguerra. Otro caso notable es, sin duda, el de Blas de Otero ${ }^{86}$, quien se

82. Gerardo Diego, "Un poeta nuevo», Obras completas..., vol. VIII, págs. 809-811. Vid. Francisco Javier Díez de Revenga, «Introducción», Gerardo Diego-José Hierro, Cuaderno de amigos, ed. Francisco Javier Díez de Revenga, Madrid, Devenir, 2005, págs. 1011. También se reproduce allí el artículo citado en págs. 33-35.

83. Incluido en Poesía (1923), se incorporó a Canción (1936), con las variantes que se incluyen en el texto enviado a Hierro.

84. Vid. Ricardo Gullón, «Juan Ramón Jiménez y La Isla de los Ratones», Op. cit., págs. 153176. Rosa Fernández Lera y Andrés del Rey Sayagüés, La Imprenta Bedia. (Santander, 19482004). Una aproximación a sus impresos, Madrid, Fundación Gerardo Diego-Ollero y Ramos, 2005.

85. «Epistolario...», págs. 304-305.

86. Lucía Montejo Gurruchaga, "La huella de Juan Ramón Jiménez en la obra de Blas de Otero", Anuario de Letras, México, vol. XXVIII, 1990, págs. 307-325. Vid. Lucía 
define en «Me complace más que el mar» como «el vasco universal, pero sin presumir tanto como el moguereńo». Una de las prosas de Historias fingidas y verdaderas (1970) lleva por título "Como de mirada, como de reproche», que remite ya directamente al contexto juanramoniano que evoca, pues el título procede de la dedicatoria de Pastorales (1905) a Gregorio Martínez Sierra: "Gregorio: el campo tiene una mirada serena, como de mirada, como de reproche, en el verdor tierno y triste de sus valles y en los remansos dormidos de sus ríos». Efectivamente, el texto, que va a evocar la memoria de las lecturas juanramonianas (el poeta leyó Pastorales en 1934) y el paisaje de refugio en la casa familiar de Orozco, se tiñe del tono pastoral de los poemas de la primera época del moguereńo para recordar y reprochar al yo narrativo:

¿Por qué rompiste tantos versos? Sólo ha quedado la carretera de Barambio, usted miró desde la ventana y se sentó luego en una silla que olía a cerezo: tomó un papel amarillo y leyó a media voz unos versos que tenían algo de Pastorales, aquel libro que pidió un poco ansiosamente en una triste biblioteca municipal.

El propio poeta nos remite a la presencia juanramoniana en su poesía. Tras la crisis de 1944, en la que el poeta "rompió todos sus versos», como puede leerse en "A la inmensa mayoría», sólo unos pocos poemas se salvarán, y tan sólo uno de ellos anterior a ese año se incorpora a Ángel fieramente humano (1950); precisamente "Los muertos», titulado posteriormente "Aldea», que había sido escrito en noviembre de 1940 y que evoca los muertos de la guerra civil desde el paisaje de Orozco, con claros tintes del Juan Ramón de Pastorales:

$$
\begin{aligned}
& \text { La sangre -nuestros muertos- se levanta } \\
& \text { con el humo del pueblo silencioso; } \\
& \text { en la sombra del río, aun más hermoso, } \\
& \text { el chopo antiguo, al contemplarse, canta. }
\end{aligned}
$$

Es significativo que cada vez que en los textos de Blas de Otero aparezca evocado el paisaje de Orozco, refugio de la infancia para el poeta adulto, va a ser a través de referencias que remiten al modelo de las Pastorales de Juan Ramón, o de Rimas, Arias tristes y Jardines lejanos; como en "Orozco», de Que trata de España (1964), o como en la prosa «El valle», de Historias fingidas $y$ verdaderas. Pero la huella juanramoniana en la obra de Blas de

Complutense, 1988. 
Otero se puede seguir perfectamente desde su prehistoria poética hasta sus últimos poemas. Efectivamente, en algunos de sus poemas olvidados, escritos en los prolegómenos de la guerra civil es evidente la huella juanramoniana. Así, por ejemplo, no es difícil oír el eco del moguereño en "Campanita de resurrección», uno de los primeros poemas que publica el bilbaíno, el 20 de abril de 1935, en las páginas de la Federación Vizcaína de Estudiantes Católicos en el diario El Pueblo Vasco; o unos meses más tarde, el 10 de noviembre de 1935, en «La niña cogía flores»:
La niña cogía flores
entre las rosas del huerto;
por cada flor que cortaba
me hacía un sentimiento...
Igual que dos mariposas
iban sus manos; de un vuelo
como el vuelo de sus manos
nunca las rosas supieron...

O en las «Baladitas humildes» que publica en la revista Luises en los albores de la guerra civil; una de ellas, «Paz», va encabezada con los versos finales de «Hora inmensa» («Sólo turban la paz una campana, un pájaro... / ¡Parece que lo eterno se coje con la mano!»), en El silencio de oro, que resuenan en los versos del bilbaíno:
¡Qué sensación de mar escondido, en el campo, aquel azul de cielo luminoso y aquel perfil de monte acantilado!

Y no es extraño que el poema que le dedique en 1938 a su amigo Jaime Delclaux, «En la muerte de Jaime», vaya encabezado por unos versos del Juan Ramón admirado por ambos poetas, pertenecientes al Diario de un poeta reciencasado («-Sí - dice el día-. No...»).

Pero la presencia juanramoniana se deja sentir en la poesía de madurez de Blas de Otero continuamente. El primer texto de Ángel fieramente humano se titulaba inicialmente "Lo eterno" y la referencia implícita al mundo juanramoniano articulaba buena parte del diálogo intertextual del poema, con claras huellas del moguereńo («mecen los árboles el silencio verde»); del mismo modo que los versos iniciales de «Vivo y mortal» remiten indirectamente a la cosmovisión juanramoniana:

Sé que hay estrellas, luminosos mares 
de fuego, inhabitados paraísos, cadenas de planetas, cielos lisos

Es todo un mundo, y todo un lenguaje que le daba sentido, lo que se pone en cuestión en los poemas de Otero, y el referente directo es el lenguaje juanramoniano. Por eso la «rosa» emblemática del andaluz va a ser inscrita en un nuevo contexto simbólico en la poesía del vasco («La Tierra»):
De tierra y mar, de fuego y sombra pura esta rosa redonda, reclinada en el espacio, rosa volteada por las manos de Dios, ¡cómo procura

Es ahí donde ha de inscribirse la referencia indirecta a los versos del poema inicial de Piedra y cielo (“iNo le toques ya más, / que así es la rosa!») en los siguientes de "Tabla rasa», incluido en Redoble de conciencia (1951): "(Aquí el poeta se volvió a la rosa: / mas no la miréis más, se difumina)». La alusión volverá a aparecer años más tarde, en «No lo toques ya más», incluido en Que trata de España (1964) con un claro juego de desplazamiento semántico:

Fray Bartolomé de las Casas dice negro.

Bernal Díaz del Castillo dice rosa.

Dejémoslo en blanco (o plata) y encarnado (o sangre).

«La rosa» volverá a aparecer, sintetizando las visiones simbólicas diferentes, en una prosa de Historias fingidas y verdaderas, vinculada también al paisaje mítico de Orozco y a la evocación del poema de Juan Ramón:

De todas las rosas de la tierra, aquella de una tarde de agosto en un rincón del valle de Orozco. Estoy seguro que aun perdura, contra todas las leyes de la estética. Así un buen poema, que, como decía el otro, no hay que tocarlo más.

En Ancia (1958) se incorpora un poema, "No cuando muera he de callar...», que articula varios juegos intertextuales («Epístola satírica y censoria al Conde Duque de Olivares», de Quevedo; un romance popular, etc.) y que lleva como epígrafe un verso de «Mirlo fiel» («Eternidad, hora ensanchada»), de La estación total con las canciones de la nueva luz, cuyo eco se retoma en el interior del poema: «Con todo el tiempo-oh eternidad-abierto». En «Escrito con lluvia», de Que trata de España (1964), Ángel González ${ }^{87}$ percibía el eco

87. Ángel González, «La intertextualidad en la obra de Blas de Otero», La poesía y..., 
de «La gloria» («También yo alumbro, ahora, en esta cueva...»), de Piedra y cielo, y en el poema se deslizan unos versos ("y olvida el daño que te hiciste, / la espalda de Matilde / y su sexo convexo") que evocan claramente otros de «Estampa de otoño» en Poemas mágicos y dolientes: «los ojos de Clotilde / y la dulzura albina de su sexo». La Clotilde juanramoniana volverá a aparecer en otro texto con reminiscencias del moguereño como es "Creemos los nombres", en Historias fingidas y verdaderas ("pero la pureza del idioma es igual a la de Clotilde»). También en Que trata de España encontramos un poema («Belleza que yo he visto ¡no te borres ya nunca!») que toma su título de unos versos de "Mi sitio", incluido en El silencio de oro:

\section{Belleza que yo he visto ¡no te borres nunca! \\ Porque seas eterna ¡yo quiero ser eterno!}

La «lluvia» simbólica, tan característica de la poesía de Blas de Otero, tal como se manifiesta en "1923», con un juego de geminación («Llueve en Bilbao y llueve, llueve, llueve / livianamente, [...] / mansamente llueve»), puede tener como origen unos versos de "Lluvia de otoño", en Olvidanzas («Y en mi corazón ardiente, / llueve, llueve dulcemente»). La «musa vestida y desnudada" de "Aquí hay verbena olorosa", tiene claras reminiscencias juanramonianas. En Mientras (1970), un texto de tono elegíaco y crítico, como muchos de la última etapa blasoteriana, lleva por significativo título el comienzo de «El viaje definitivo»: "Y yo me iré». En fin, las prosas de Historias fingidas y verdaderas están inspiradas en buena medida por la prosa de Juan Ramón Jiménez y la huella del andaluz es clara a lo largo de todo el libro, tanto en referencias directas en los títulos ("Creemos los nombres», «La rosa»), como en citas, alusiones y otras referencias («El demonio y sus cómplices», "Brotes nuevos», "Un momento", "Como de mirada, como de reproche»). La presencia juanramoniana en la obra de Blas de Otero se extiende más allá de los juegos referenciales que se han apuntado, a modelos temáticos, formales y técnicos, como la reflexión metapoética, el juego intertextual, las yuxtaposiciones espacio-temporales, el empleo del collage, el cromatismo de algunos textos con su funcionalidad simbólica, los modelos versales empleados en otros, la musicalidad de ciertas composiciones, etc.

Hasta el punto de que puede afirmarse que Blas de Otero es en la poesía de posguerra uno de los herederos más destacados de la obra de Juan Ramón

págs. 266-286. 
Jiménez.

Celaya, Hierro y Otero ilustran tres líneas diferentes dentro de los poetas recogidos en la Antología consultada que muestran una clara influencia de la poesía juanramoniana. Su rastro puede seguirse sin demasiada dificultad en otros poetas allí antologados, como en el Eugenio de Nora de Amor prometido (1945), pero también en muchos de los poemas de Contemplación del tiempo (1948) («Canto interior», "Miro a los álamos», "Tierra y aire», entre otros) o en la sección "Canciones en el aire», de Siempre (1953); como en el José María Valverde de La Espera (1949), que tanto llamó la atención de Juan Ramón ( La masa total es de calidad lírica sin innecesaria perfección», le escribirá el 22 de julio de $1949^{88}$ ), etc. En otros, como en Rafael Morales, pienso que la presencia juanramoniana se deja sentir más claramente en los libros últimos, sobre todo en Entre tantos adioses (1993) y en Poemas de la luz y la palabra (2003), donde se incluye significativamente el poema «Belleza», un homenaje a Juan Ramón Jiménez:

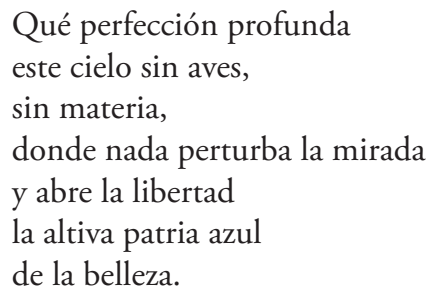

Pero la presencia juanramoniana puede rastrearse también en otros poetas no recogidos en aquella antología, aunque próximos a la estética representada en ella, como Ángela Figuera, Leopoldo de Luis, Ramón de Garciasol, José Luis Cano, etc. El caso de la autora de Mujer de barro es significativo, por cuanto marca desde un primer momento, en su correspondencia con Blas de Otero, su distanciamiento de la poesía pura («estoy harta de leer versos perfectos, inaguantables con su forma impecable e implacable, insoportables de pureza, de trascendencia y preciosismo»), pero al mismo tiempo define su poesía como «inactual» y "sencilla», en oposición a la de «estos días del tremendismo, surrealismo, deshumanización, etc.» ${ }^{89}$. Sin embargo, el poeta le contestará de modo radical: "Yo no puedo creer que una poesía lo sea

88. Juan Ramón Jiménez, Cartas literarias..., pág. 169.

89. Cartas de Ángela Figuera a Blas de Otero de 23-VII-1949 y 22-I-1949, respectivamente, citadas por Sabina de la Cruz, "Una mujer, una poesía, una época», Zurgai, monográfico

dedicado a Ángela Figuera, 1987, pág. 26. Vid. José Ramón Zabala Aguirre, Ángela Figuera: una poesía en la encrucijada, San Sebastián, Universidad de Deusto, 1994, págs. 100-101. 
(poesía) si no encierra o produce belleza» ${ }^{90}$. Pese a todo, la presencia de Juan Ramón Jiménez es indudable en la obra de Ángela Figuera, y así la reconoce el moguereño en carta que le remite por la recepción de Soria pura (1949): «Ando por los versos de usted como por un campo de árboles, aguas, arenas, animales, matas, vientos, alguna persona natural. Y me encuentro en ese campo a gusto. Ésta es mi crítica» ${ }^{91}$. En "Árbol», por ejemplo, resuena claramente el eco de «Yo no seré yo, muerte» de Belleza:

Tú no serás después que yo no sea.

El peso inexorable de mi muerte te abatirá, rotundo, como rayo.

El eco de los versos del moguereño se siente a lo largo de todo el libro: "¡Qué fecundo / brotar en tallo y en raíz: eterna!» («En tierra»), «En otra primavera, / yo brotaré en tus hojas» («Álamo»), "Cuando ya no haya árboles, / yo brotaré una selva, un bosque nuevo, / vivo en el solo ardor de mi palabra» ("Cortad el árbol»), «¿Qué piedra de eternidad / me hincaron en las entrañas?» («Cańaveral»), etc. Incluso el «Homenaje» final, dedicado a Antonio Machado, presenta mayores resonancias de los versos de Juan Ramón. También en su libro anterior, Mujer de barro (1948) es claramente perceptible el eco de los versos de Juan Ramón ( $H$ Hemos encontrado / nuestro divino centro / para girar, eternos, vivos, astros...», en "Revelación del éxtasis»), hasta el punto de que toda la sección final del libro, "El fruto redondo", puede leerse como un juego intertextual, casi un pastiche, con la poesía del moguereño, en que no son extrańas las referencias a «El otońado»; las referencias a Juan Ramón aparecen claras desde los primeros versos: «Sí, también yo quisiera ser palabra desnuda. / Ser un ala sin plumas en un cielo sin aire». En este sentido, poemas posteriores en los que arrecia la crítica al purismo poético, al esteta («Poeta», "Posguerra», "El cielo» o "La rosa incómoda»), han de leerse en la misma estela hermenéutica en la que se ubicaba "Para un esteta», de José Hierro, más como un diálogo implícito con un sujeto desdoblado, que como un ataque a la poesía juanramoniana.

El grupo cordobés de la revista Cántico se decantó muy pronto por un tipo de poesía que huyera del neorromantiscismo rehumanizado que caracterizaba a una parte importante de la poesía de posguerra. Desde el primer número de la revista, sus promotores se encargaron de defender una

90. Carta de Blas de Otero a Ángela Figuera de 16-XII-1949, citada por Sabina de la Cruz, «La irrenunciable belleza», Zurgai, monográfico Que trata de Blas de Otero, 1988, pág. 16.

91. Juan Ramón Jiménez, Cartas literarias..., págs. 175-176. 
poesía fundada «en la importancia esencial de la imagen en el poema» ${ }^{92}$ y la metáfora como su resorte central, que les lleva a enlazar con Juan Ramón Jiménez, el 27 y Gabriel Miró ${ }^{93}$. De la poética juanramoniana interesa a Cántico, y a su teórico principal, Ricardo Molina la capacidad para destilar su rica sensibilidad al margen del lenguaje lexicalizado, dejando un núcleo de misterio que puede ser descubierto por la intuición ${ }^{94}$ :

Sus versos -escribirá Ricardo Molina en el $\mathrm{n}^{\circ} 8$ (diciembre de 1948-enero de 1949)-, un solo verso, nos hacen olvidarlo todo para vivir delicadamente en un mundo de emoción pura y de belleza. El núcleo sustancial del poema se mantiene invulnerable a la intelección, irradiando inagotablemente sus dones de ensueño.

Es esa dimensión mistérica del ensueño, que señala Molina en la poesía de Juan Ramón, la que trasciende a sus Elegías de Sandua (1948), en que no es extrańo oír el eco de los versos de la etapa más engalanada del moguereño ( «iA qué he venido entre los verdes árboles / del bosque traspasado de armonía?»), o al más delicado de Pastorales:

En el fondo del bosque hay un prado suave.

Por las cañadas verdes fluye un río de esquilas

y en la orilla del bosque, bordeando su sombra un arroyo apagado.

Cuando derrite el cielo el sol de julio

buscan los bueyes las espesas sombras.

O incluso el tono panteísta característico de algunos de sus poemas, que ya aparece en alguno de los textos de El río de los ángeles (1945) ("y así, gozosos, líquidos, disolvernos en ondas, / en claras ondas plateadas, verdes...»). En Corimbo (1949), se incluirá un significativo homenaje a Juan Ramón Jiménez, "Contemplación de la rosa»:

El silencio cautivo en el color

prende en su calma el alma

92. Cántico, no 1 , octubre de 1947, pág. 12. Cito por la edición facsímil: Córdoba, Diputación Provincial, 1983.

93. Guillermo Carnero, El grupo "Cántico» de Córdoba. Un episodio clave de la historia de la poesía española de postguerra, Madrid, Editora Nacional, 1976, págs. 39 y ss. Existe reedición reciente ampliada: Madrid, Visor, 2009.

94. Ibid., pág. 45. 
confundiendo hombre y rosa íntimo aroma y fragancia bella sin que sepan de espacio ni distancia.

La poesía primera de Pablo García Baena «muestra una notable influencia del Juan Ramón Jiménez modernista, influencia que le perseguirá durante muchos años» ${ }^{95}$. Fue Juan Bernier quien, a comienzos de los años cuarenta, introdujo al joven García Baena en la lectura del moguereño, y en él encontró el poeta un modelo de exploración de la sensibilidad y de expresión en un léxico delicado y rico, además de una musicalidad y una capacidad imaginativa destacadas. No es difícil encontrar ecos del Juan Ramón más modernista en Rumor oculto (1946) ("Al escuchar mi oído la brisa de tus voces, / [...] sentí en mi alma un roce de blandas plumas blancas»), y la huella de aquella poesía "fastuosa de tesoros» se puede rastrear a lo largo de toda su obra, desde Antiguo muchacho (1950) ("Jardines de amatista, emergiendo sombríos / con pálidos estanques y la perla del cisne, desde la lejanía pronunciarán tu nombre y pulsará el ocaso sus laúdes de luna, / latentes como vírgenes corazones secretos»), hasta Los Campos Elíseos (2006). En Antes que el tiempo acabe (1978), se incluirá un homenaje a Juan Ramón, "Jardín galante», donde la presencia del modernista se transforma casi en un pastiche de su poesía hacia 1910 (véase "Otro jardín galante»). Pero también puede hallarse en su poesía buena parte de la carnalidad y el erotismo característicos de algunos de los libros de Juan Ramón, como Jardines lejanos o Laberinto, en poemas que, simbólicamente, claman por una liberación carnal. Pienso, por ejemplo, en «Llanto por la hija de Jephté», pero también en poemas posteriores, como «Viernes Santo», «Delfos», «David» o "Bobby», entre otros; aunque en algunos de estos poemas de García Baena hay un referente netamente religioso, también de raigambre modernista, pero ausente en los textos de Juan Ramón. Y quizás podría hallarse en el influjo juanramoniano una de las raíces, con Cernuda al otro lado, de esa "conciencia trágica del tiempo» que Molina definió en el poeta sevillano y que inunda el sentimiento elegíaco característico de los principales autores de Cántico. Pero también ha de señalarse la vinculación de Cántico con la poesía sensitiva juanramoniana, en la construcción de un ejercicio poético que parte de la evocación de la memoria sensorial; son los sentidos los que actúan como motor del desarrollo poético, reconstruyendo todo un mundo a través del poema, como puede verse claramente, por ejemplo, en «Bajo la dulce lámpara», de Pablo García Baena.

La relación de Juan Ramón con José García Nieto, el poeta más destacado

95. Ibidem, pág. 67. 
del grupo de Garcilaso, debió de comenzar con la colaboración del moguereño en el $\mathrm{n}^{\circ} 10$ (febrero de 1944), y se extendió hasta la muerte del primero ${ }^{96}$. Cuando el poeta asturiano inicia, en enero de 1952, la trayectoria de Poesía Española no duda en solicitar la colaboración del andaluz. El moguereño, que ha recibido un ejemplar del reciente premio Adonais de 1950, Dama de soledad, bajo cuya firma, Juana García Noreña, parece esconderse la autoría de José García Nieto, le envía un poema "Eco de dama de soledad», escrito en Riverdale en 1951 bajo la referencia de uno de los poemas del libro, «El eco»; el poema se publicará en el $n^{\circ} 12$ (diciembre de 1952) de Poesía Española y se incorporará al proyecto De ríos que se van ${ }^{97}$. Unos meses más tarde, en abril de 1953, la revista publica un nuevo texto del poeta exiliado en primicia mundial, el poema de Dios deseado y deseante «Si la belleza inmensa me responde o no» («Buscándote como te estoy buscando...») y en el $n^{\circ} 25$ (enero de 1954) se publica otro poema que se incorporará a De ríos que se van, el libro del que ha comenzado a dar a conocer algunos poemas («Sólo tú», «Sobre una nieve», "Mi Guadiana me dice», «Nuestro ser de ilusión», "Mirándole las manos» $\mathrm{y}$ «Este inmenso Atlántico») en el n 85 (enero de 1953) de la revista Insula y en los números de mayo y julio de la revista malagueña Caracola: «Los dos en más realidad» («Yo vine del allí libre...»). Para entonces García Nieto le ha enviado a Juan Ramón, ya en Hato Rey, Puerto Rico, la edición no venal de los Sonetos por mi hija, que el poeta recibe con palabras elogiosas ("iQué hermosos son!»). En esa misma carta, fechada el 27 de febrero de 1954, el poeta le ofrece a García Nieto:

Tengo terminado un largo poema, Espacio, que es una síntesis de un libro mayor. Publiqué un tercio de este poema, hace unos diez años, en los Cuadernos americanos, de Méjico, y el resto es inédito. ¿Le interesaría a usted darlo en Poesía española? Creo que se puede meter en seis o siete pájinas, con un tipo de letra intermedio y no escesivamente apretado. Si lo prefiere usted, puedo dar solo lo inédito, es decir, la tercera estrofa, pero es claro que el poema perdería su unidad, los Cuadernos americanos no circulan por España y, además, ha pasado mucho tiempo desde la fecha en que le digo que publiqué una parte del poema ${ }^{98}$.

Efectivamente, Espacio, uno de los poemas más importantes de la literatura

96. José María Martínez Cachero, Op. cit., pág. 80.

97. Vid. Rosario Hiriart, La mirada poética de José García Nieto, Barcelona, Icaria, 1990, pág. 51-60.

98. Juan Ramón Jiménez, Cartas literarias..., págs. 274-275. Vid. Alfonso Alegre Heitzmann, "Génesis, contexto...», págs. 5-10. 
española del siglo XX, aparecerá por primera vez completo en el $\mathrm{n}^{\circ} 28$ de Poesía Española, correspondiente a abril de 1954 (págs. 1-11). Pero la relación de Juan Ramón con García Nieto y con Poesía Española no concluye con la publicación de una de las joyas poéticas españolas del siglo pasado: en el $n^{\circ} 60$ (diciembre de 1956) se le dedica un homenaje, con motivo de la concesión del Premio Nobel, en el que colaborarán, entre otros, Carmen Conde, Gerardo Diego, Victoriano Crémer, José Hierro, García Nieto, etc.; con motivo de su muerte, la revista organizaría un nuevo homenaje al poeta.

A comienzos de los años cincuenta las revistas poéticas andaluzas se muestran muy activas y la figura de Juan Ramón comienza a cobrar una presencia importante en ellas ${ }^{99}$. Desde la malagueńa Caracola, a la que deseará larga vida desde Puerto Rico en 1953 ("Que vivas mucho, Caracola malagueña, respetada por todos y alerta en tu arena de tu playa que yo pisé respetuoso en 1924, en 1926, ¡casa del inglés!») y donde se publicarán entre 1953 y 1957 numerosos poemas de En el otro costado, Una colina meridiana, Dios deseado y deseante y De ríos que se van, además de las cartas de y a Georgina Hübner, hasta las norteafricanas Ketama, que dio a conocer «Las piedras constantes» («i Vida, preciosa vida...») en su $n^{\circ} 3$ (junio de 1954) y Al-Motamid, que, en el $n^{\circ} 28$ (septiembre de 1954) difundió en España "¿Al fin poetas?» («No está la muerte nuestra bajo tierra...»). Pero, por el aliento especial que supuso para un grupo de jóvenes autores, destacan sobre todo las colaboraciones de Juan Ramón en la gaditana Platero ${ }^{100}$ entre 1951 y 1954, revista que nace, de la mano de Fernando Quiñones, obviamente bajo la advocación del moguereño, que abrirá el $n^{\circ} 5$ (mayo de 1951) con dos poemas de Dios deseado y deseante ("Con mi mitad de allí» y «Todas las nubes arden»). Juan Ramón, en una de sus enfermizas recaídas, no volverá a colaborar en la revista gaditana hasta el $\mathrm{n}^{\circ} 18$ (1953), donde, junto a cinco «Romances revividos del tiempo de Platero. 1903-1905» («La acacia de Padrediós», "La ruina», "Aquel prado», «La nevada» y "Donde fue su primavera»), envía una afectuosa nota en la que promete "desquitarme de mi silencio de enfermo involuntario de dos años. Les enviaré algo para cada

99. El 17 de diciembre de 1953 le confiesa a Ricardo Gullón (Conversaciones con Juan Ramón, Madrid, Taurus, 1958, pág. 119): «Ahora estoy enviando colaboración a varias revistas españolas: Platero, Caracola, Poesía Española, Cuadernos Hispanoamericanos... Envío a casi todas colecciones de aforismos, y quiero mandar algo a Pino Ojeda, tan valiente en sus hojas de Alisio».

100. Puede verse la edición facsímil de Platero a cargo de Manuel J. Ramos Ortega, quien en el «Prólogo» detalla la relación del grupo gaditano con el moguereño: Sevilla, Fundación El Monte, 2000. 
número; inédito y revivido de todos mis tiempos». Y así será, pues en el no 19, se incluye la prosa "Ciriaca Marmolejo», perteneciente al proyecto Casa azulmarino; el $\mathrm{n}^{\circ} 20$ se inicia con "Paloma ofendida», inédito hasta entonces y perteneciente a En el otro costado; el n ${ }^{\circ} 22$ se cerraba con una serie de aforismos juanramonianos, bajo el título "Autocrítica»; el n 23 (1954) se abría con otro poema inédito («La palma seca»), fechado en 1942, de En el otro costado; y el $\mathrm{n}^{\circ} 24$, último que la revista gaditana publicaría, se iniciaba con un nuevo «Romance revivido del tiempo de Platero (1903-1954)»: «Un amanecer con Cristo». Más allá de las importantes colaboraciones, la influencia de Juan Ramón en los autores de Platero se deja sentir en diversas facetas. Es significativa, por ejemplo, la atención que el moguereño prestó a la poesía de la joven Pilar Paz Pasamar, cuyo poema "El reclinatorio» ("¿Quién colocó mentira sobre el suelo / para las descansadas bienvenidas?»), aparecido en el $\mathrm{n}^{\circ} 18$ (1953) de la revista gaditana, alabó el poeta («nada más fuerte que la delicadeza exacta» $\left.{ }^{101}\right)$, o a su libro Mara (1951), que le sirvió para establecer un vínculo enriquecedor con el poeta exiliado. En cierto modo, Pilar Paz Pasamar heredaba la línea ascético panteísta que el moguereño venía trazando en su poesía desde el inicio, y que había venido acentuando en sus libros del exilio. Pero la presencia juanramoniana puede percibirse también en algunas de las prosas poéticas que un joven Fernando Quiñones adelanta en la revista gaditana. Allí también aparecerán los primeros poemas notables (aunque ya había publicado algún texto en Espadaña) de José Manuel Caballero Bonald. Además de en estas revistas andaluzas, los nuevos textos de Juan Ramón van publicándose en diversas revistas españolas a comienzos de los años cincuenta, como las ya citadas Ínsula, La Isla de los Ratones o Poesía Española. Clavileño, que había publicado un artículo de Germán Bleiberg («El lírico absoluto: Juan Ramón Jiménez») en $n^{\circ} 10$ (1951), va a incluir un par de años más tarde, en el n 24 (1953) un «Recuerdo a José Ortega y Gasset» que el moguereño escribe como contribución al homenaje que la revista rinde al filósofo. La madrileńa Indice, fundada en 1951 por Juan Fernández Figueroa, será una de las revistas que acoja con frecuencia los textos juanramonianos a comienzos de los años cincuenta, a veces incluso reproduciendo fragmentos sin permiso del autor, como ocurrió en el n ${ }^{\circ} 62$ (mayo de 1953) con unos párrafos de la conferencia "Crisis del espíritu en la poesía española contemporánea» publicados bajo el título "Juan Ramón habla de poesía»; en el $n^{\circ} 64$ se insertó una carta del poeta al director

101. Juan Ramón Jiménez, Cartas. Antología, ed. Francisco Garfias, Madrid, Espasa-Calpe, 1992, pág. 363. 
explicando el asunto ${ }^{102}$. En el $\mathrm{n}^{\circ} 60$ (febrero-marzo de 1953) de Índice se adelanta el poema «Este árbol que me parte» («Cada vez oigo mejor») perteneciente al proyecto En el otro costado. Juan Ramón volvería a publicar en la revista madrileña en el homenaje que ésta le rinde a Baroja ( $\left.\mathrm{n}^{\circ} 115\right)$, con motivo de la publicación de Maremágnum, de Jorge Guillén ( $\mathrm{n}^{\circ} 124$ ) o evocando la figura del poeta argentino Macedonio Fernández $\left(\mathrm{n}^{\circ} 128\right)$. También la madrileña Correo literario, dirigida por Leopoldo Panero desde 1950, a pesar de iniciarse con un artículo de Juan Aparicio con resonancias claramente anti-juanramonianas ("A la mayoría, siempre»), publicaría tres prosas poéticas de Juan Ramón en el número correspondiente a julio de 1954, pertenecientes al proyecto Dios deseado y deseante: "Los pasos de la entraña que encontré» («En esta abierta estela vuelan...»), «Choque de pecho con espalda» («Eres lo limitado de mi órbita...») y «El corazón de todo el cuerpo» («Yo fui y vine contigo, dios,...»). La canaria Alisio, dirigida por Pino Ojeda, publicaría en el número correspondiente a mayo de 1954 uno de los últimos poemas del proyecto Dios deseado y deseante: «Un dios en blanco» ("Como en el infinito, dios»).

Andrew P. Debicki señaló la «disminución del interés por Juan Ramón Jiménez, como también por Jorge Guillén y Federico García Lorca, tendiendo a estereotiparse su poesía como excesivamente pura e inhumana» ${ }^{103}$, entre los jóvenes poetas que comienzan a publicar a mitad de la década de los años cincuenta. Sin embargo, parece indudable que, de una manera o de otra, la presencia de Antonio Machado y Juan Ramón Jiménez resulta insoslayable en la formación de los poetas a la altura del medio siglo ${ }^{104}$, pese a la lectura restrictiva que de la obra del moguereño hiciera José María Castellet en Veinte años de poesía española, en defensa de una poesía de manifiesta actitud realista, que supliera a la de "tradición simbolista»: "encontramos en Juan Ramón Jiménez una particular exigencia de la pureza poética, una extravagante obsesión por la soledad, una maniática concepción abstracta de la belleza y un tinte edulcorado y tristón en sus poemas» ${ }^{105}$. No es extraño que tras esos juicios, que remiten fundamentalmente a la perspectiva que del poeta andaluz habían plasmado sobre todo Luis Cernuda, en sus Estudios

102. Juan Ramón Jiménez, Cartas literarias..., págs. 326-328.

103. Andrew P. Debicki, Poesía del conocimiento. La generación española de 1956-1971, Madrid-Gijón, Júcar, 1986, pág. 20. Véase la réplica de Josep Maria Sala Valldaura, La fotografia de una sombra. Instantáneas de la generación poética de los cincuenta, Barcelona, Anthropos, 1993, págs. 46-47.

104. Juan García Hortelano, El grupo poético de los años 50. (Una antología), Madrid, Taurus, 1978, págs. 24-25.

105. José María Castellet, Op. cit., pág. 42. 
sobre poesía española contemporánea (1957), pero también Max Aub, en La poesía española contemporánea (1947), Castellet considerara que la poesía de Juan Ramón estaba, «en tantos aspectos, lejos de nosotros»; lo que le llevará a no incluir ningún poema suyo en la antología. Es significativo, por ejemplo, que Jaime Gil de Biedma, en defensa de una postura éticoestética próxima a la de Luis Cernuda, rechace la obra del onubense ${ }^{106}$, pero a la hora de explicar su propia evolución poética evoca en sus palabras ("yo creía que quería ser poeta, pero en el fondo quería ser poema») las que Juan Ramón le había escrito a Cernuda en 1943: «Escribir no es sino una preparación para no escribir, para el estado de gracia poético, intelectual o sensitivo. Ser uno poesía y no poeta» ${ }^{107}$. No obstante, una buena parte de los poetas que se dan a conocer hacia la mitad de los ańos cincuenta van a defender el magisterio de Juan Ramón en su poesía. "Juan Ramón Jiménez me produjo un deslumbramiento que desencadenó unas influencias todavía visibles en mi escritura», declarará Ángel González; y subrayará más adelante: «todo lo que he escrito yo, en lo fundamental se lo debo a Juan Ramón Jiménez» ${ }^{108}$. Para José Manuel Caballero Bonald, «así como Juan Ramón ha ejercido una influencia evidente en toda la poesía que ha venido detrás, Machado se ha quedado como en seco» ${ }^{109}$. José Agustín Goytisolo, por su parte, reconocerá que "Juan Ramón Jiménez, con su tratamiento del poema puro y desnudo y su hondura y voluntad de una obra bien hecha es el iniciador de la mejor poesía que ha venido después, y hasta nuestros días» ${ }^{110}$. Francisco Brines señalará: «Yo he sido muy fiel a Juan Ramón Jiménez [...], y la Segunda antolojía poética [...] fue mi Biblia personal» ${ }^{11}$. Carlos Sahagún, por su parte, también subraya el magisterio de Juan Ramón en su poesía: «La Segunda antolojía poética [...] fue mi libro de cabecera durante muchos ańos en la adolescencia» ${ }^{112}$. Las referencias, puntuales en este caso, podrían extenderse para demostrar la importante presencia de la obra de Juan Ramón en la poesía de los autores que comienzan a publicar en torno a la mitad de los años cincuenta. Pero habría que preguntarse qué Juan Ramón influye en cada momento y en cada autor, porque la poesía polifónica del

106. Vid. Jaime Gil de Biedma, "Como en sí mismo, al fin», El pie de la letra. Ensayos 1955-1979, Barcelona, Crítica, 1980, pág. 334.

107. Juan Ramón Jiménez, Cartas literarias..., pág. 59.

108. Miguel Munárriz, ed., Encuentros con el 50. La voz poética de una generación, Oviedo, Fundación Municipal de Cultura, 1990, pág. 54-55.

109. Ibidem, pág. 55.

110. Ibidem, pág. 55.

111. Ibidem, pág. 71.

112. Ibidem, pág. 91. 
moguereño tiene un registro especial para cada lector atento. Es evidente, por ejemplo, que la obra de Juan Ramón supone un modelo de educación de la sensibilidad poética y estética en la mayor parte de los autores de este período, pero también es verdad que, mientras muchos de ellos aprenden a llevar a cabo la exploración de la memoria sensitiva que realizan en sus poemas siguiendo la pauta del poeta andaluz, otros inciden en la dimensión metapoética y autorreferencial de su obra y otros apuntan un proceso de depuración léxica que les lleva a indagar por espacios comunes con los del poeta investigador de la "transparencia», o con los del asceta panenteísta que busca una religión de la palabra en un Dios creado por la propia escritura como objetivación de la conciencia. Pero a todos ellos les influye, sin ninguna duda, una concepción, como la juanramoniana, de la poesía como un modo de indagación, como un medio de conocimiento.

Quizás sea Ángel González uno de los autores en los que más claras son las referencias a la obra de Juan Ramón, cuya lectura intensa podemos fechar hacia $1944^{113}$. En el de Moguer, Ángel González encuentra, al menos, tres vías fundamentales para el desarrollo de su propia poesía: en primer lugar, en su primera poesía (Rimas, sobre todo), encuentra un enlace con lo mejor de la tradición poética romántica española y una síntesis con el decadentismo inmediatamente posterior que le lleva a una objetivación sentimental, en una modernización de esa tradición ${ }^{114}$; en segundo lugar, en su poesía desnuda descubre el proceso de humanización que subyace y la decantación de un lenguaje que tiende cada vez más a la identificación fondo-forma, es decir, a la comunicabilidad; por último, le interesa de la poesía del andaluz todo el proceso de indagación metapoética ${ }^{115}$, en tanto en cuanto éste revela una indagación metafísica como modo de instalarse en el mundo, en la realidad, a través de la belleza deificada, pero también como modo de trascender del tiempo en el tiempo. No hay, por lo tanto, contradicción alguna entre una poesía que se quiere histórica («La Historia de la poesía [...] no es más que un fragmento de la Historia, que siempre es del hombre» ${ }^{116}$ ) y una poesía que pretende vencer al tiempo en el tiempo ${ }^{117}$. La reflexión metapoética,

113. Ángel González, «Introducción», Poemas, Madrid, Cátedra, 1984, págs. 25.

114. Vid. Ángel González, La poesía y sus circunstancias..., págs. 135-175. Ángel González, Juan Ramón Jiménez, Madrid-Gijón, Júcar, 1974, passim.

115. Vid. John C. Wilcox, «Ángel González’s intertextualization of Juan Ramón Jiménez», The discovery of poetry: Essays in honor of Andrew P. Debicki, ed. Roberta Jonson, Boulder, Society of Spanish and Spanish-American Studies, 2003, págs. 35-59.

116. Ángel González, «Poesía y compromiso», Francisco Ribes, Poesía última, Madrid, Taurus, 1963, pág. 57.

117. Ángel González, Juan Ramón Jiménez..., pág. 175. 
tan característica en la obra de González, encuentra así su entronque con la obra del andaluz, en una búsqueda, desde una perspectiva diferente, de la capacidad performativa de la palabra poética, de sus posibilidades actuativas en la transformación de un mundo que enuncia; pero también la constatación nítidamente juanramoniana, heredada de Bécquer y la tradición romántica, de la insuficiencia del lenguaje, de la «cortedad del decir», que revela el poema «Me falta una palabra», de Áspero mundo (1956), un libro que muestra su raigambre juanramoniana desde su mismo título. En la sección "Canciones» no es difícil percibir el eco del Juan Ramón de Canción, unido muchas veces a Bécquer. Las descripciones de la sección "Acariciado mundo» recuerdan los modelos juanramonianos («Jardín»), incluso en la adjetivación («las verdinegras zarzas», «una amarilla paz de hojas caídas», "agridulce plata otoñal») o en los juegos aliterativos («Leve rumor de luces y de brisas / rodaba por el valle, se acercaba»). Tal vez pueda percibirse en "Predicador injustamente perseguido", de Grado elemental (1962), un juego irónico con un poema en prosa titulado «Un imitador de Billy Sunday», en Diario de un poeta reciencasado ${ }^{118}$. Tratado de urbanismo (1967) supone un cambio importante en la evolución poética de González, así como la investigación en modelos irónicos y paródicos, que indagan en la «antipoesía», en cuyas raíces se encuentra "cierto rencor frente a las palabras inútiles», que revela también un «amor por lo parodiado» ${ }^{119}$. Es en ese sentido en el que han de entenderse las constantes referencias a Juan Ramón en su poesía posterior, pero también con un claro sentido autorreferencial, como en "Ahí, donde fracasan las palabras», de Procedimientos narrativos (1972), que puede leerse a la luz del mencionado «Me falta una palabra», o toda la sección «Metapoesía» (por ejemplo, «Orden. [Poética a la que otros se aplican]» remite directamente a "Quisiera que mi libro...", de Piedra y cielo) en Muestra, corregida y aumentada, de algunos procedimientos narrativos... (1977), pero también en «Inmortalidad de la nada», «Elegía pura», etc., en otras secciones del libro. "A la poesía», con su identificación poesía-mujer, puede leerse como una reescritura de "Vino, primero, pura...», y, desde una perspectiva diferente, también la «Oda a los nuevos bardos» puede leerse como intertextualización del poema juanramoniano. En la sección «Diatribas, homenajes» de Prosemas o menos (1985), encontramos claras referencias irónicas a la obra del moguereño, que han de leerse también desde una perspectiva autocrítica. El poema inicial («Pétalo a pétalo, memorizó la rosa...») ironiza el proceso de estetización y emblematización de la «rosa»

118. John C. Wilcox, Op. cit., págs. 42-44.

119. Ángel González, «Introducción», Poemas..., págs. 18-20. 
característico de la poesía juanramoniana. Y la referencia se une al poema "J.R.J.», siglas del poeta, donde se refiere una vez más el conocido verso «No lo [sic] toques ya más». Este último texto es toda una recreación de la estética juanramoniana, del trabajo implícito que conlleva la depuración estética emprendida por el poeta, aunque no está exento de una crítica explícita, que se extiende no sólo al «cansado de su nombre», sino también a la propia escritura precedente. En este sentido, buena parte de la sección mencionada remite a la poética heredera de la tradición modernista en la que se forma el lenguaje poético contemporáneo en España, y contra la que, en cierto modo, trata de alzarse la poesía de Ángel González al menos desde Tratado de urbanismo para definirse netamente en los "prosemas»: "A un joven versificador», "Tanto universalizar...», "Sinestesia», etc. En esa línea ha de leerse el empleo irónico del lenguaje del primer Juan Ramón en «Avanzaba de espaldas aquel río» ${ }^{120}$. En Otoños y otras luces (2001) el juego referencial se desarrolla con semejante intencionalidad, siendo abundantes los ecos de la obra de Juan Ramón: "Aquí o allí» juega con el hipotexto juanramoniano de "¿Soy yo quien anda, esta noche...", de Jardines lejanos; "También un nombre puede modificar un cuerpo» evoca las referencias de «Estampa de otońo», de Poemas mágicos y dolientes, a la vez que los versos finales juegan con claros referentes juanramonianos («en el principio no era el verbo. / [...] la transparencia, el llanto, la alegría: / todo estaba ya en ti. / Los nombres que te invento no te crean») constituyendo una respuesta a la estética idealista de "A un poeta (para un libro no escrito)», de Poemas impersonales, y "Acción», de Eternidades; en "Versos amebeos» se funde la oración con la referencia juanramoniana («Hágase hoy en mí tu transparencia, / sea yo en tu claridad»); etc.

José Manuel Caballero Bonald ha subrayado la impronta que el «vértigo imaginativo» de la poesía, pero también de la prosa, de Juan Ramón Jiménez dejó en él desde el principio. Pero también ha señalado la importancia que la reflexión sobre la palabra tiene en la poesía del moguereño y cómo esa preocupación se transmite a través de los poetas del 27 hasta su generación y su obra. Desde la Segunda antolojía poética hasta el monumental Espacio, la poesía de Juan Ramón delimita un campo de influencia muy atractivo para el poeta jerezano. El propio autor de Las adivinaciones (1952) ha señalado que su primer libro se encontraba «a medio camino entre la erótica religiosidad juanramoniana y el ritual panteísta aleixandrino» ${ }^{121}$, y

120. Vid. Martha LaFollete Miller, Politics and Verbal Play. The Ludic Poetry of Ángel González, Cranbury, New Jersey \& London, Associated University Presses, 1995, págs. 155157.

121. José Manuel Caballero Bonald, «Introducción», Selección natural, Madrid, Cátedra, 
es ahí donde han de colocarse algunos de sus poemas más significativos, donde se imbrica ese "destino de buscador de Dios» con el hallazgo de la «belleza», tal como puede verse en «Ceniza son mis labios». Pero también la reflexión sobre la palabra y su insuficiencia, tan característica de su obra posterior, arranca de sus primeros libros (véase «Las adivinaciones», «Signos favorables», «Transfiguración de lo perdido», «Música de fondo», etc.), y ha de vincularse, al menos parcialmente, a la estética juanramoniana. La dimensión temporalista de su poesía, además de la esencia cambiante de la palabra poética, facilita también el proceso de desdoblamiento del personaje poético tan característico de la poesía juanramoniana, que encontramos, por ejemplo, en "Cráter del tiempo", y ya de modo objetivado en los poemas de Descrédito del héroe (1977). Pero es en esa fe en la palabra poética, que crea en el momento de nombrar, donde puede percibirse en la poesía de Caballero Bonald el legado principal del moguereño: «Empieza a ser verdad mientras lo escribo", resume un verso de Diario de Argónida (1997). Es en la palabra poética donde se inscribe la matriz temporal, donde el tiempo se hace esencia verbal («ese atajo del tiempo en que se aloja / la palabra matriz de las palabras», como se lee en "Atajo del tiempo»), y, en esa búsqueda, el poeta de Manual de infractores (2005) volverá a invocar la escritura transparente y el verso del moguereño: «La transparencia, Dios, la transparencia» («La transparencia»). Aunque para el jerezano la escritura poética muestra a cada paso «la deficiencia de los signos» («Ab origine») y, en consecuencia, «escribir y no hacerlo son renuncias idénticas» («Recursos inútiles»), invirtiendo así el idealismo verbal juanramoniano.

La poesía de Claudio Rodríguez ha sido definida, en su proceso evolutivo, como el tránsito del poeta dionisíaco al poeta prometeico, de aquel que vive la «ebriedad», definitoria de su primer libro, Don de la ebriedad (1953), la contemplación, la visión epifánica del mundo, a aquel que es consciente de la progresiva pérdida de esa capacidad contemplativa y ha de luchar por instalarse en un mundo que le es ajeno, con una mirada ética cada vez más desengañada ${ }^{122}$. Ahora bien, esa progresiva pérdida de la «visión», de la «ebriedad», de la «contemplación» implica en la obra de Claudio Rodríguez una progresiva confianza en la palabra poética, un progresivo desplazamiento de un idealismo platónico a un realismo lingüístico que culmina en Casi una leyenda (1991), título de evidentes resonancias juanramonianas. De este modo, la escritura poética, objetivada en los textos, tiende a desplazar la

1984, pág. 20.

122. Luis García Jambrina, De la ebriedad a la leyenda. La trayectoria poética de Claudio Rodríguez, Salamanca, Ediciones Universidad de Salamanca, 1999, págs. 23-43. 
memoria histórica a su dimensión legendaria, desplazando paralelamente la idea del «origen» al lenguaje poético. La memoria, en consecuencia, va a existir en Casi una leyenda en cuanto memoria de la obra poética y en cuanto memoria de la vida como leyenda, adquiriendo así una clara dimensión metapoética. En este sentido, puede aparecer la evolución poética de Claudio Rodríguez con cierto paralelismo a la que lleva a cabo Juan Ramón en su última etapa, teniendo en cuenta las radicales diferencias existentes entre una y otra, vinculándose a una semejante orientación metafísica derivada de una pareja concepción gnoseológica ${ }^{123}$. Sin lugar a dudas, son Tiempo y Espacio los libros cuyo reflejo puede percibirse más claramente en Casi una leyenda $a^{124}$, en una concepción común de un discurso fuertemente temporalizado que con un tono elegíaco va diciéndose sin estridencias ni rupturas, fundiendo vida y escritura como una misma materia que cobra sentido en el poema, donde no son extrańas las reflexiones ontológicas, sobre todo en los poemas de «Nunca vi muerte tan muerta». Pero es indudable, y esto ya era patente en El vuelo de la celebración (1976), que muchos de los momentos extáticos de algunos de los poemas de Claudio Rodríguez en este libro («Revelación de la sombra», "La mañana del búho», etc.) evocan configuraciones semejantes del poeta de La estación total. No es vano, en este sentido, que «transparencia» $\mathrm{y}$ "transfiguración» sean términos reiterados (y estructuradores) en Casi una leyenda.

Una actitud significativa para comprender la relación de la obra juanramoniana con los poetas que comienzan a publicar hacia la mitad de los años cincuenta, es la que manifiesta José Ángel Valente, quien, en su artículo "Juan Ramón Jiménez en la tradición poética del medio siglo», publicado en la revista Índice en febrero de $1957^{125}$, venía a coincidir con la opinión de Cernuda y con la que expondría Castellet tan sólo unos años más tarde, al señalar que el poeta de Moguer «no rebasó nunca los supuestos centrales que hicieron posible el simbolismo, y toda su obra [...] permanece esencialmente dentro del área de aquél». Dicha actitud derivaría, según entendía Valente en 1957, hacia una "sentimentalidad clausurada", que coincide con una «exaltación romántica del yo» y con un «idealismo» que supone una «visión radical y totalizadora de la irrealidad del mundo y de la suprema, solitaria y suficiente realidad del yo», frente a la postura machadiana que percibe

123. Luis García Jambrina, Claudio Rodríguez y la tradición literaria, Valladolid, Junta de Castilla y León, 1999, págs. 49-50.

124. Tomás Sánchez Santiago, «Hacia otras relaciones», Zurgai, monográfico Con Claudio Rodríguez, julio de 2006, págs. 89-90.

125. Recogido en José Ángel Valente, Las palabras de la tribu, Barcelona, Tusquets, 1994, $2^{\mathrm{a}}$ ed., págs. 83-92. 
ya la necesidad de una apertura al «prójimo», la «busca del tú esencial». Sin embargo, pese a esa actitud crítica contra una cosmovisión que no había conseguido salir del simbolismo, Valente subrayaba en la obra de Juan Ramón su capacidad de introspección, su "progresión circular alrededor de un centro absolutamente inmóvil», el pensamiento de la temporalidad, la autoconciencia y una actitud cognoscitiva que se realiza en la escritura poética, que revela un paralelismo esencial con aquella que describe en su poética para la antología Poesía última (1963), escrita ese mismo año de 1957, aunque publicada más tarde: «La poesía es para mí, antes que cualquier otra cosa, un medio de conocimiento de la realidad» ${ }^{126}$. Es en esa capacidad cognoscitiva donde coinciden Valente y buena parte de sus coetáneos con la poesía de Juan Ramón; la poesía se concibe, así, como un modo de conocimiento, de introspección, de revelación, que acontece en la palabra y cuyo objeto es en el caso del andaluz el «yo» y en el caso del gallego «la realidad». Con razón apunta Valente en una nota posterior su admiración por la calidad estética, "por la extraordinaria apertura de la obra final del poeta», aun no coincidiendo con la «actitud estética» que revela. Y así lo pondría de manifiesto poco antes de su muerte: «Sus libros finales lo llevan en el mundo de la experiencia poética mucho más allá de lo que alcanzó la llamada Generación del 27» ${ }^{127}$. Efectivamente, la evolución poética que Valente describe en Juan Ramón le sería aplicable a su propia obra, como un proceso de introspección circular hacia un centro único siempre ausente; porque lo que Valente encuentra no es el "yo» de esa «sentimentalidad clausurada» que revela su ruina, sino precisamente su ausencia. No es extraño, así, que el último libro del poeta gallego, Fragmentos de un libro futuro (2000), llevara como epígrafe, junto a unos versos de Arnaut Daniel, el verso inicial de Dios deseado y deseante ("Dios del venir, te siento entre mis manos»), en tanto en cuanto, como había apuntado, el moguereño se apropia de las formas de expresión de la mística pero con una inversión del proceso. No cabe duda de que el último libro de Valente se integra en una tradición de indagación en la palabra poética semejante a la que adopta la obra final de Juan Ramón Jiménez, y no es extraño, en consecuencia, que maneje un lenguaje semejante, de una desnudez radical y de una capacidad simbólica absoluta, sin perder un ápice de su narratividad: «Entre el sauce apenas rozado por las aguas y la torre amarilla, el tiempo mira al tiempo y lo devora», "Pájaro del olvido / jamás te tuve más cierto en mi memoria»,

126. José Ángel Valente, «Conocimiento y comunicación», Poesía última..., pág. 155.

127. José Ángel Valente, «Juan Ramón Jiménez en su nuestra luz», $A B C, 14$ de marzo de 1999, pág. 81. 
«la pura raíz del aire», etc. En cierto modo, el propio Valente, evocando las palabras que el poeta escribiera a Cernuda, había situado a Juan Ramón dentro de la tradición de la "cortedad del decir», en la que tanto investigaría su obra. Pero la huella juanramoniana es fácilmente rastreable en los primeros libros del poeta, en los que puede encontrarse incluso un diálogo implícito con la estética purista. Así, por ejemplo, "La rosa necesaria», de $A$ modo de esperanza (1955), viene a enfrentarse a la rosa emblemática juanramoniana («La rosa no; / la rosa sólo / para ser entregada») y reaparece años más tarde en «Forma», de Breve son (1968), como «la rosa quemada». Poemas a Lázaro (1960) se abre con una cita del verso final de "Obra», incluido en Canción, con la que, en cierto modo, dialoga el texto en su conjunto: "¡qué poco tiempo más único!». «El poema», de El inocente (1970), parece enfrentarse de modo radical a la estética purista, evocando los versos de «A un poeta (por un libro no escrito)»:

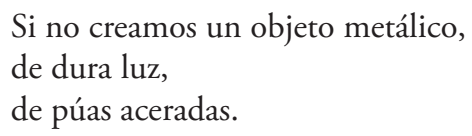

Francisco Brines es otro poeta que ha reivindicado la presencia de Juan Ramón Jiménez en su obra: «Yo siempre creí que los rastros de Juan Ramón en mí serían evidentes y poderosos - declara el poeta en 1980-, y para siempre, pues en él eduqué mi sensibilidad adolescente con enamoramiento casi enfermizo» ${ }^{128}$. Efectivamente no es difícil rastrear la huella del moguereño y de Antonio Machado en su etapa más próxima al simbolismo en un poemario, como Las brasas (1960), que surge de una voluntad de sugerencia más que de matización de pensamientos, con una llamada constante a la percepción sensorial ${ }^{129}$. Desde citas y referencias transparentes hasta la creación de «atmósferas» poéticas características del Juan Ramón simbolista, la presencia de la obra del andaluz es constante en el primer libro de Brines. Y no es extraño que así sea en un poeta que, como el de Moguer, ha hecho del tiempo el centro temático de su obra poética, compartiendo algunos aspectos con la filosofía existencial, y de la percepción personal del mundo su núcleo, aunque consciente de la dimensión social que ello implica: «Los poetas, al hablar de sí mismos, siempre están hablando de los demás». En este sentido, Brines coincide con Juan Ramón en esa dimensión temporal de la poesía, que le va a hacer aprovechar diversos recursos formales,

128. H. Alvarado Tenorio, «Entrevista a Francisco Brines», Cuervo, n 1, 1980, pág. 25.

129. José Luis Gómez Toré, La mirada elegíaca. El espacio y la memoria en la poesía de Francisco Brines, Valencia, Pre-Textos, 2002, pág. 19. 
como las yuxtaposiciones y superposiciones temporales, tal como puede verse en "Mere Road», "Evocación de presencia», "Relato superviviente», "Reminiscencias», "Las campanas de St. Peter in the East», etc. Pero es, sin duda, en esa evocación sensorial de la memoria sensitiva, en la construcción de espacios y paisajes que funcionan como correlatos objetivos de estados de ánimo, donde la poesía de Brines se aproxima más a la del Andaluz Universal. En este sentido, puede percibirse de modo claro su huella en Las brasas, donde encontramos referencias directas a versos juanramonianos. Así, los versos iniciales de "Hay que mecer el tallo de esta hierba...» («nadie / lo toque demasiado, [...] / que está linda, / linda la rosa de esta casa») funcionan desde el reiterado hipotexto del poema inicial de Piedra y cielo. El poema inicial remite en su forma (romance asonantado) a uno de los modelos más queridos por Juan Ramón. Y en el siguiente poema («El balcón da al jardín. Las tapias bajas...») se percibe claramente el eco de Jardines lejanos y especialmente el del poema "¿Soy yo quien anda, esta noche...». Pero hay en el libro referencias que, directa o indirectamente, remiten al mundo juanramoniano, cargado de cierto decadentismo finisecular:

\section{Vuelven las estaciones del destierro, y dormita el sillón, y los papeles sin resplandor sobre la mesa vieja.}

los libros, amarillos

Ya no lucha la tarde y se hace rosa la luz en su cabeza sensitiva.

En los versos finales del penúltimo poema puede percibirse un eco inverso de la transustanciación que se recrea en «El otońado». La huella juanramoniana se difumina en los siguientes libros de Brines, pero muchos de los recursos ejercitados en Las brasas reaparecerán en poemas posteriores.

La presencia juanramoniana también puede percibirse con cierto relieve en la obra de Antonio Gamoneda, lector temprano de la obra del moguereño, que, como aquél (recuérdense sus palabras en "Poesía y Literatura»), hace partir su poesía de una distinción radical, heredera de los planteamientos del simbolismo, y expuesta ya por Verlaine en su "Art poétique», con la literatura, tal como ha repetido el poeta leonés ${ }^{130}$; mientras que aquélla limita

130. Véase, por ejemplo, su «Discurso en la entrega del Premio Cervantes 2006». 
con la música y se funde con la vida, la literatura es fundamentalmente un género de ficción, no un género de dicción como considera la poesía. «La poesía es canto, no expresión bella», había escrito Gamoneda en 1963 en "Poesía y conciencia» ${ }^{131}$, y esa concepción va a ir arrastrando su obra hacia una esencialidad, hacia una renuncia al «virtuosismo» pareja a la que, según confesaba a Ricardo Gullón, lleva a cabo Juan Ramón en su última etapa de producción: «según voy haciéndome más viejo, siento mayor deseo de quitar al poema, a mis cosas, todo el virtuosismo» ${ }^{132}$; "el virtuosismo empezó a ser secundario y hasta sospechoso", declarará Gamoneda, refiriéndose a su escritura en torno a Blues castellano (1982, aunque escrito 19611966 ${ }^{133}$. Fruto de ese proceso de depuración, de eliminación progresiva del «virtuosismo» poético, será la supresión de la rima, incluso del verso, y su sustitución por períodos, por cláusulas poéticas, a partir de Descripción de la mentira (1977), que ponen en cuestión los resortes genéricos tradicionales de la escritura poética; algo que aproxima al leonés a la escritura de Espacio, en la que confluye con otros elementos fundamentales (dimensión simbólica y abstractiva, yuxtaposiciones temporales, etc.), y de Leyenda. Pero la huella de Juan Ramón se percibe en la poesía de Gamoneda desde sus primeros poemas, en los que, junto a la influencia fundamental del cancionero y de la poesía lorquiana, se perciben ecos del moguereño: "Te beberé el cabello...», "Si una rosa infinita me estallase en el pecho...», "Únicamente porque muere, canta / mi palabra desnuda y retorcida», etc. Pero es en Sublevación inmóvil (1960) donde la influencia juanramoniana se percibe más claramente, a través de la búsqueda, del deseo, de la «sed» de Belleza, que define al protagonista poético, con una dimensión amplia, ética, moral y existencial, que vincula «belleza y dolor». "Herido / de transparencia, mi / corazón se oculta en la belleza», escribe Gamoneda en los primeros pasos del libro, sintetizando la poética de su libro, una belleza cordial, distante de esa «belleza azul / [que] cruza lejos». Es la "Criatura de luz / fugitiva», que le lleva a «subir a / la claridad y el frío», "la belleza / [que] no proporciona dulces sueños», pero que hace aspirar a la fusión absoluta de corte juanramoniano:

Piedra viva, fúndete

dentro de mis ojos, dame

131. Antonio Gamoneda, «Poesía y conciencia», Insula, n 204, noviembre de 1963, pág. 4.

132. Ricardo Gullón, Conversaciones..., pág. 152.

133. Antonio Gamoneda, El cuerpo de los simbolos, Madrid, Huerga \& Fierro, 1997, pág. 179. Vid. José Antonio Expósito Hernández, La obra poética de Antonio Gamoneda, Madrid, Universidad Complutense, 2003, págs. 58-59. 
tu consistencia, pon una pequeña eternidad en mí.

Pero, sobre todo, se percibe ya en Sublevación inmóvil una búsqueda estética, una voluntad de conocimiento a través de la palabra poética, al mismo tiempo que un proceso depurativo, de desnudez de la expresión, que pueden vincular la obra de Gamoneda a la del moguereño. Descripción de la mentira, en este sentido, confluye en muchos aspectos, y no sólo el formal, con Espacio: en la introspección, en la fusión espacio-temporal como búsqueda de una experiencia originaria, en la ruptura del verso tradicional, en la estructura narrativa que emula, en el empleo del monólogo interior, en la construcción simbólica del lenguaje, etc. Son rasgos que entroncarán los libros siguientes con la tradición que renueva el poema juanramoniano, en la conciencia de que es el lenguaje el que habla a través del poeta y no al contrario. Fiel a la lectura de Juan Ramón, que tanto le había influido en sus años de formación, en 1981, con motivo del homenaje que Cuadernos Hispanoamericanos le dedica, Gamoneda publicará allí una «Lápida a Juan Ramón», reescrita posteriormente para su libro Lápidas (1987):

A donde tienes que ir es a ti solo

$$
\text { J.R.J. }
$$

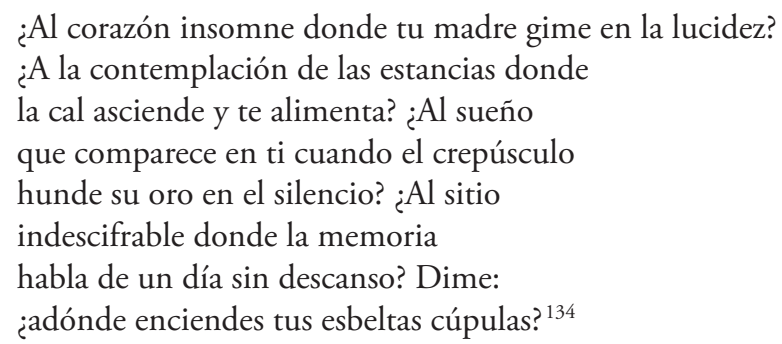

La presencia juanramoniana puede encontrarse en otros poetas que comienzan a publicar a lo largo de los años cincuenta y comienzos de los sesenta. Es indudable su huella, por ejemplo, en la obra de Ángel Crespo, quien trabajó denodadamente en la obra del moguereño durante su estancia en Puerto Rico, publicando Guerra en España y escribiendo su Juan Ramón Jiménez y la pintura. También puede percibirse la presencia juanramoniana

en la poesía de José Corredor-Matheos, en José Agustín Goytisolo, en Joaquín Marco, en Alfonso Costafreda y un largo etcétera.

134. Antonio Gamoneda, «Lápida a Juan Ramón», Cuadernos Hispanoamericanos, n³76-378, octubre-diciembre de 1981, pág. 162. 
Es cierto que entre los poetas que comienzan a publicar en la segunda mitad de los años sesenta y primeros setenta la presencia juanramoniana queda diluida entre otras más ostensibles y visibles, como la de T.S. Eliot, Octavio Paz, Ezra Pound, Aleixandre, etc. Además de que muchos de los jóvenes poetas de entonces, siguiendo la línea que había trazado Cernuda y que habían continuado Castellet, Gil de Biedma o Carlos Barral, entendían que el tiempo del moguereńo había concluido, y, a pesar de la admiración que algunos de ellos, guiados por el juicio de Paz, sienten por Espacio y por una parte de su poesía última, las declaraciones en su contra son habituales. En las poéticas de Nueve novísimos poetas españoles (1970), tan sólo se cita un par de veces a Juan Ramón y es para criticar «los delirantes excesos de J.R.J. (véase 'Estética y Ética Estética')» (Antonio Martínez Sarrión), o para evocar, en el caso de Félix de Azúa, una lectura colegial de Platero y yo. Sin embargo, pese a las declaraciones de entonces, la huella juanramoniana puede seguirse en estos y otros poetas de esa promoción y, por ejemplo, no se encuentra muy alejado de la estética esencialista del andaluz un poeta como Jaime Siles, o las reflexiones metapoéticas de Guillermo Carnero, que ironizará sobre Animal de fondo en su "Variación I. Domus Aurea», o la poesía de Pere Gimferrer en L'espai desert o en Aparicions, etc. Pero su huella es perceptible también en la obra de Antonio Colinas, Diego Jesús Jiménez, Luis Alberto de Cuenca, Luis Antonio de Villena, y otros poetas. Es evidente que la presencia juanramoniana resulta insoslayable. Pero estos poetas fundan ya un paradigma nuevo que no puede ni debe adscribirse al largo período de la posguerra, y exceden ya los límites trazados al comienzo de este estudio. 